\title{
Primary Feldspar in the Semarkona LL3.00 Chondrite: Constraints on Chondrule Formation and Secondary Alteration
}

DOI:

10.1111/maps.13194

\section{Document Version}

Accepted author manuscript

Link to publication record in Manchester Research Explorer

Citation for published version (APA):

Lewis, J., \& Jones, R. (2019). Primary Feldspar in the Semarkona LL3.00 Chondrite: Constraints on Chondrule Formation and Secondary Alteration. Metoritics and Planetary Science, 54(1). https://doi.org/10.1111/maps.13194

\section{Published in:}

Metoritics and Planetary Science

\section{Citing this paper}

Please note that where the full-text provided on Manchester Research Explorer is the Author Accepted Manuscript or Proof version this may differ from the final Published version. If citing, it is advised that you check and use the publisher's definitive version.

\section{General rights}

Copyright and moral rights for the publications made accessible in the Research Explorer are retained by the authors and/or other copyright owners and it is a condition of accessing publications that users recognise and abide by the legal requirements associated with these rights.

\section{Takedown policy}

If you believe that this document breaches copyright please refer to the University of Manchester's Takedown Procedures [http://man.ac.uk/04Y6Bo] or contact uml.scholarlycommunications@manchester.ac.uk providing relevant details, so we can investigate your claim.

\section{OPEN ACCESS}


Primary Feldspar in the Semarkona LL3.00 Chondrite:

Constraints on Chondrule Formation and Secondary Alteration

Jonathan A. Lewis ${ }^{1}$ and Rhian H. Jones ${ }^{1,2}$

${ }^{1}$ Department of Earth and Planetary Sciences, University of New Mexico, Albuquerque, NM 87131

${ }^{2}$ School of Earth and Environmental Sciences, University of Manchester, Manchester, M13 9PL, UK

\begin{abstract}
Feldspar in ordinary chondrites (OCs) is often associated with thermal metamorphism, as a secondary mineral that forms from the crystallization of matrix and chondrule mesostasis. However, studies of feldspar in equilibrated OCs show that there is a range of plagioclase compositions within chondrules, some of which may be primary products of chondrule crystallization. It is important to recognize primary feldspar within chondrules because it can be used to help understand the secondary effects of thermal metamorphism and aqueous alteration. The presence of primary feldspar also provides important petrologic constraints on chondrule formation timescales. We undertook a careful study of Semarkona (LL3.00) and observed feldspar in $18 \%$ of chondrules. The feldspar is plagioclase covering a wide range of compositions $\left(\mathrm{An}_{2}-\mathrm{An}_{99}\right)$ with little $\mathrm{K}$-feldspar component $\left(<\mathrm{Or}_{3}\right)$. We show that plagioclase is a primary igneous phase, based on grain morphology and compositions consistent with growth from a melt having the bulk compositions of the host chondrules. Based on experimental studies, the presence of plagioclase suggests chondrules cooled slowly at temperatures close to the solidus. We also observed several secondary features consistent with the aqueous alteration. These features include zoning of $\mathrm{Na}$ and $\mathrm{Ca}$ in plagioclase, heterogeneity in plagioclase compositions in altered chondrules, development of porosity from the dissolution of chondrule glass, and alteration of glass to phyllosilicates. Alteration of major Al-bearing phases, like plagioclase and glass, has important implications for interpretations of ages derived from $\mathrm{Al}-\mathrm{Mg}$ dating of chondrules, if they have been affected by secondary processes.
\end{abstract}

\title{
Introduction
}

Feldspar in ordinary chondrites (OCs) is commonly considered to be a secondary phase that forms during thermal metamorphism. As chondrule mesostasis glass, often feldspathic in composition, and chondrite matrix recrystallize, plagioclase and other phases develop in what has historically been treated as a solid-state, temperature-dependent process (Huss et al. 2006). The classification scheme of Van Schmus and Wood (1967), used to differentiate degrees of thermal metamorphism, describes the crystallization of chondrule mesostasis into albite as an important feature of the effect of thermal metamorphism. According to this classification scheme, fine-grained albite crystallizes by petrologic type 4 and then undergoes textural equilibration through types 5 and 6, ultimately resulting in grains of albite $>50 \mu \mathrm{m}$ in size (Huss et al. 2006; Van Schmus and Wood 1967).

However, recent studies of feldspar in equilibrated OCs (Kovach and Jones 2010; Lewis and Jones 2016) show that the general model of Van Schmus and Wood (1967) does not fully define the feldspar equilibration process or the range in compositions and textures found in OC feldspar. Plagioclase is not solely albitic in composition and a wide range of plagioclase compositions $\left(\mathrm{An}_{2}-\mathrm{An}_{88}\right)$ is present in relict chondrules in type $4 \mathrm{~L}$ and LL chondrites (Kovach and Jones 2010; Lewis and Jones 2016). Only in type 6 chondrites is feldspar equilibrated chemically, as well as texturally, to an albitic composition of $\sim \mathrm{An}_{11}$.

The wide range of feldspar compositions within chondrules in type $4 \mathrm{~L}$ and LL chondrites is plausibly derived from variable initial mesostasis compositions. However, chondrules may also contain primary igneous plagioclase, with a range of compositions that could reflect the compositions of plagioclase observed in type 4 OCs. Primary, igneous anorthitic feldspar has been described in Type I chondrules in OCs (Huss et al. 2001; Russell et al. 2000) but it is not well characterized, unlike similar occurrences in carbonaceous chondrites (CCs) (Brearley and Jones 1998; Wick and Jones 2012). Al-rich chondrules in OCs also contain primary anorthite that is useful for age dating using Al-Mg systematics 
(e.g., Huss et al. 2001). Although Type II chondrules in OCs are relatively rich in $\mathrm{Na}$ and $\mathrm{K}$, albitic plagioclase or alkali feldspar is not generally observed (Jones 1990). Grossman and Brearley (2005) noted that crystalline albite is present within some Semarkona chondrules, but did not indicate whether it is primary or secondary in origin.

To understand how secondary plagioclase develops during metamorphism, it is essential to know the abundance and composition of primary plagioclase. The mineralogical and chemical changes that affect chondrule mesostasis during thermal metamorphism depend on the composition and initial crystallinity of the mesostasis, in addition to temperature and available fluids. The presence of primary feldspar can influence the subsequent crystallization of the mesostasis glass by providing surfaces on which secondary plagioclase can nucleate. Plagioclase is also affected by alkali metasomatism, so secondary effects recorded in primary plagioclase can provide an indicator of the presence of fluids in type 3 chondrites. Plagioclase alteration can affect Al-Mg systematics resulting in low precision isochrons or ages that are difficult to interpret. In addition to its importance in terms of interpreting metamorphism, understanding the origin and development of primary feldspar can help constrain chondrule cooling rates, an important parameter in chondrule formation models (Connolly and Jones 2016).

We have investigated the presence and characteristics of primary igneous plagioclase within chondrules of the LL3.00 chondrite Semarkona. Semarkona is the least thermally metamorphosed OC fall with a maximum metamorphic temperature estimated to be less than $260^{\circ} \mathrm{C}$ (Alexander et al. 1989). It is the ideal sample in which to investigate primary chondrule minerals because chondrule mesostasis glass has not undergone crystallization (Huss et al. 2006). The mineralogy and petrology of Semarkona chondrules were studied extensively by Jones and Scott (1989) and Jones (1990, 1994, 1996), but primary igneous plagioclase was not recognized in those studies. Marked improvements in SEM technology has enabled higher resolution investigations into chondrule mineralogy and allowed for studies on phases too small to be fully characterized in earlier studies. We show that primary igneous plagioclase is abundant in Semarkona chondrules and that careful observations of plagioclase are important for interpreting the effects of metamorphism, alteration, and the results of $\mathrm{Al}-\mathrm{Mg}$ isotope systematics.

\section{Samples \& Analytical Methods}

For this study, we examined a single thin section of Semarkona from the Institute of Meteoritics Collection at the University of New Mexico, UNM 549. Feldspar was identified using backscattered electron (BSE) imaging and energy-dispersive spectroscopic (EDS) analysis on an FEI Quanta 3D Field Emission Gun Scanning Electron Microscope (FEG-SEM) at the University of New Mexico. High contrast BSE images were captured at $10 \mathrm{kV}$ and $16 \mathrm{nA}$. Cathodoluminescence (CL) images were acquired at the Williamson Research Centre, University of Manchester using a CITL Cold Cathode CL $8200 \mathrm{MK} 3$ with optical stage operated at $15-20 \mathrm{kV}$ and 300-400 $\mu \mathrm{A}$.

Quantitative wavelength-dispersive spectroscopic (WDS) analysis was performed on a JEOL 8200 Electron Probe Microanalyzer (EPMA) at the University of New Mexico operated at 10-15 kV and $10 \mathrm{nA}$ with a focused beam. The low accelerating voltage was used to minimize the interaction volume when analyzing small feldspar grains. We used the following standards: Taylor olivine ( $\mathrm{Mg}, \mathrm{Fe})$, Taylor albite $(\mathrm{Na}, \mathrm{K})$, Taylor orthoclase (K, Al, Si), and a doped diopside (Ca, $\mathrm{Cr}, \mathrm{Mn})$. We used time dependent intensity corrections on $\mathrm{Na}$ using the Probe for EPMA software to compensate for the effects of $\mathrm{Na}$ migration in Na-bearing plagioclase during focused-beam analysis.

We determined bulk silicate compositions for four chondrules, based on quantitative WDS maps obtained using the EPMA. 300x300 pixel maps were acquired in two passes using an $80 \mathrm{~ms} / \mathrm{px}$ dwell time and a 1-3 $\mu \mathrm{m}$ spot size. This provided coverage of between $300 \times 300 \mu \mathrm{m}$ and $900 \times 900 \mu \mathrm{m}$, depending on the size of the chondrule. The resulting intensity maps were processed using mean atomic number (MAN) background corrections to produce quantitative oxide maps. MAN curves were generated using the following Taylor standards: olivine, albite, orthoclase, chromite, spessartine, $\mathrm{MgO}$, hematite, and nickel and additional standards: doped diopside, labradorite, and sodalite. Chondrules were masked in Adobe Photoshop and the bulk silicate compositions of the chondrules were calculated. We used a custom MATLAB script to identify the chondrule pixels in which analytical sums lie between $90 \%$ and $110 \%$. In 
addition, pixels with $\mathrm{SiO}_{2}$ content less than $20 \%$ were omitted to eliminate $\mathrm{Fe}-\mathrm{Ni}$ metal and sulfides. Densities were determined for each pixel based on the assigned mineral phase and the bulk silicate composition of each chondrule was calculated as the mean density-weighted composition of accepted pixels.

A section from Ch 28 was prepared using a focused ion beam (FIB) on the FEI Quanta 3D Dualbeam FEG-SEM/FIB with a final polish conducted at $5 \mathrm{kV}$ to reduce surface amorphization. The section was imaged at the University of New Mexico using a JEOL 2010F Scanning Transmission Electron Microscope (STEM) operated at $200 \mathrm{kV}$ in scanning mode using a high-angle annular dark-field (HAADF) detector. A qualitative EDS map was acquired over a $2.4 \mu \mathrm{m}$ x $1.8 \mu \mathrm{m}$ region.

\section{$\underline{\text { Results }}$}

Figure 1 shows a BSE map of thin section UNM 549 in which feldspar-bearing chondrules are outlined in white. Chondrules referred to in the text, figures, and tables are labeled in Fig. 1 by chondrule number. Eighteen percent of chondrules were found to contain primary igneous feldspar and consist of a range of sizes and textures described below.

\section{Petrography}

Examples of chondrules that contain near-endmember albite and anorthite (Ch3 and $\mathrm{Ch} 36$, respectively) are illustrated in Fig. 2. Ch3 (Fig. 2a) is a Type II (FeO-rich) porphyritic olivine-pyroxene (POP) chondrule. It is dominated by a single large $(450 \mu \mathrm{m})$ olivine grain in addition to smaller grains of olivine (up to $150 \mu \mathrm{m}$ ) and low-Ca pyroxene (up to $75 \mu \mathrm{m}$ ). The olivine grains show normal igneous zoning and the low-Ca pyroxene grains have oscillatory zoning (Fig. 2b). Calcium-rich pyroxene is present around the perimeter of the low-Ca pyroxene grains. The albite has a composition of $\mathrm{An}_{2}$ and is present predominantly along the chondrule perimeter in bunches of thin, 1-8 $\mu \mathrm{m}$ wide, laths (Fig. 2b) up to $60 \mu \mathrm{m}$ in length within the chondrule glass. Some of these laths are curved and have convex terminations indicating rapid growth. Albite luminesces bright blue in the CL image (Fig. 2b, inset), but the glass does not luminesce significantly making albite easy to recognize via CL in this, and other, albite-bearing chondrules. Along the chondrule edge, in contact with the matrix, mesostasis glass is partially altered to phyllosilicates and the albite laths are zoned subparallel to the regions of alteration (Fig. 2c).

Ch36 (Fig. 2d) is an FeO-poor barred olivine (BO) chondrule that has 10-30 $\mu$ m wide bars of forsteritic olivine. The chondrule has extensive fracturing, particularly in the central region, and appears to have been crushed. Between the olivine bars are abundant 1-6 $\mu \mathrm{m}$ wide laths of anorthite (An99, Fig. $2 \mathrm{e})$. Interstitial to the anorthite laths are small $(\sim 1 \mu \mathrm{m})$ clinopyroxene quench crystallites and minor remnant glass. The glass is largely intact but is replaced by voids in a few places throughout the chondrule. A CL image of Ch36 (Fig. 2f) shows that plagioclase luminesces light blue. Olivine bars luminesce red and are zoned, with the brightest parts toward the exterior of the grains. The mesostasis glass luminesces bright yellow along the chondrule rim and pale yellow toward the interior.

Representative BSE images of chondrules that contain plagioclase with intermediate compositions are shown in Fig. 3. Ch28 (Fig. 3a) is a Type II POP chondrule with olivine grains up to $150 \mu \mathrm{m}$ long and low-Ca pyroxene grains up to $250 \mu \mathrm{m}$ long. Similar to $\mathrm{Ch} 3$, the olivine and low-Ca pyroxene grains in $\mathrm{Ch} 28$ are zoned and $\mathrm{Ca}$-rich pyroxene is found along the perimeter of the olivine and low-Ca pyroxene grains. Several large voids (up to $370 \mu \mathrm{m}$ in diameter) are present in the chondrule interior. Albitic plagioclase (Fig. 3b) is present as 1-6 $\mu \mathrm{m}$ wide laths that are interstitial to the olivine and pyroxene grains throughout the chondrule and is zoned with a range of compositions from $\mathrm{An}_{3}$ to $\mathrm{An}_{19}$. Pores and porous phyllosilicates are present within, and between, the plagioclase laths.

A FIB section (Fig. 4a) was extracted from Ch28 (white line in Fig. 3b) to further investigate the plagioclase zoning seen in the BSE image (Fig. 3b). Plagioclase laths in the HAADF STEM image (Fig. 4b) show zoning parallel to the grain boundaries. This zoning is visible in the Ca EDS map (Fig. 4c), which shows that $\mathrm{Ca}$ is moderately enriched in the core but heterogeneously distributed from core to rim within individual laths. Between the plagioclase laths, adjacent to the low-Ca zones, are porous 
phyllosilicates. Vertical lineations in Fig. 4a, also seen in Fig. 4b inclined to the right, are a curtaining artefact produced during sample preparation.

$\mathrm{Ch} 23$ (Fig. 3c) is a Type I (FeO-poor) POP chondrule containing large low-Ca pyroxene grains up to $250 \mu \mathrm{m}$ long and smaller (up to $150 \mu \mathrm{m}$ long), zoned olivine grains. Interstitial to the major grains are 1-2 $\mu \mathrm{m}$ wide laths of intermediate plagioclase ( $\mathrm{An}_{37}$, Fig. $\left.3 \mathrm{~d}\right)$, up to $30 \mu \mathrm{m}$ long. The plagioclase laths are zoned like those in $\mathrm{Ch} 28$ and much of the mesostasis interstitial to the plagioclase laths appears to have been dissolved away as it is now void space. Calcium-rich pyroxene is found along the perimeter of the low-Ca pyroxene grains with plagioclase largely interstitial to it. However, the terminations of the plagioclase laths slightly embay into the $\mathrm{Ca}$-rich pyroxene.

Ch20 (Fig. 3e) is also a Type I POP chondrule with $30-70 \mu \mathrm{m}$ olivine grains clustered near the interior and pyroxene grains up to $120 \mu \mathrm{m}$ long near the chondrule exterior. Plagioclase is located at the center of the chondrule and occurs as 1-3 $\mu \mathrm{m}$ wide laths, up to $60 \mu \mathrm{m}$ long, with a composition of $\mathrm{An}_{66}$ (Fig. 3f). Calcium-rich pyroxene is present both interstitial to the plagioclase laths and along the low-Ca pyroxene perimeters. Like $\mathrm{Ch} 23$, some of the mesostasis glass appears to have been dissolved away, leaving voids interstitial to the plagioclase and $\mathrm{Ca}$-rich pyroxene grains.

\section{Feldspar compositions}

EPMA data for feldspar measured in 14 chondrules are presented in Fig. 5, average compositions for individual chondrules are given in Table 1, and individual analyses are tabulated in Table S1. Feldspar compositions span the full range along the $\mathrm{Ab}$-An plagioclase join, from $\mathrm{An}_{2}$ to $\mathrm{An}_{100}$. The $\mathrm{K}_{2} \mathrm{O}$ contents are minor, but increase slightly with decreasing An content to a maximum of $\mathrm{Or}_{2}$ in $\mathrm{Ch} 3\left(\mathrm{An}_{2}\right)$. No Kfeldspar was observed in any of the chondrules. The compositional range of plagioclase within each chondrule varies considerably from chondrule to chondrule. In the truncated ternary diagram in Fig. 5, each spot represents an individual analysis. On the scale to the left of Fig. 5, we illustrate the range in anorthite contents by plotting the average plagioclase composition for each chondrule with error bars representing one standard deviation of the mean.

Greater compositional ranges are correlated with secondary features such as dissolved mesostasis glass and the presence of phyllosilicates (e.g., Ch28: Figs. 3b and 4 and Ch23: Fig. 3d). Ch3 also has phyllosilicates and dissolved mesostasis glass (Fig. 2c) but a low standard deviation in its An content because only a few of the plagioclase grains in contact with the matrix have undergone alteration and the majority appear to be unaltered. Ch10 has the greatest standard deviation because only 3 points are included in the calculation and there is a 15 mol. \% spread between the highest and lowest values $\left(\mathrm{An}_{21^{-}}\right.$ $\left.\mathrm{An}_{36}\right)$. The lowest $\mathrm{An}$ value measured in Ch10 is associated with the region of greatest alteration.

Tenner (2017) and Tenner et al. (2014) have shown that plagioclase in chondrules from several highly unequilibrated chondrites can have an appreciable excess silica component, indicating an anhydrous, high-temperature origin. Based on our EPMA analyses, we see some evidence for this, but the data show a lot of scatter. The presence of a silica excess in chondrule plagioclase does not impact the results of this study, but it is an interesting feature with implications for chondrule alteration.

The $\mathrm{Cr}_{2} \mathrm{O}_{3}$ and $\mathrm{MnO}$ contents of plagioclase in all chondrules are low, typically less than 0.1 wt.\% each, and there is no correlation with anorthite content. The minor elements $\mathrm{FeO}$ and $\mathrm{MgO}$ vary greatly from chondrule to chondrule as well as within each chondrule but can be of significant abundance (up to $4.5 \mathrm{wt} . \%$ total in individual analyses). It is not clear whether these elements are incorporated into plagioclase or not, and if they are incorporated, how they are substituting into the crystal structure. The high abundances of these elements do not correlate significantly with An content as would be expected if they were directly substituting for $\mathrm{Ca}$, and the system is too reducing for Fe to be trivalent and substitute for $\mathrm{Al}$. However, the $\mathrm{Mg \#}(\mathrm{Mg} /(\mathrm{Mg}+\mathrm{Fe}))$ of the plagioclase does correlate with An content, for example atomic $\mathrm{Mg \#}=24$ and 95 for $\mathrm{An}_{2}$ and $\mathrm{An}_{99}$, respectively, suggesting that the composition is controlled during crystallization. $\mathrm{FeO}$ and $\mathrm{MgO}$ (up to 3 and $1.2 \mathrm{wt} . \%$, respectively) are commonly reported in meteoritic plagioclase over a range of compositions, summarized by Smith and Brown (1988), so the presence of these cations in our measurements is not unusual. The crystallization conditions may be such 
that the incorporation of $\mathrm{FeO}$ and $\mathrm{MgO}$ into plagioclase represent a disequilibrium feature of rapid plagioclase growth.

However, Smith and Brown (1988) caution about the over interpretation of feldspar EPMA data without careful consideration of the analytical conditions. Secondary florescence can be a major issue, particularly in Fe-rich samples. It is also possible that some of the $\mathrm{FeO}$ and $\mathrm{MgO}$ content comes from analytical overlap of adjacent phases such as Ca-rich pyroxene, metals, and sulfides. Despite using low accelerating voltages $(10-15 \mathrm{kV})$ during EPMA analysis to reduce the analytical interaction volume, the small sizes of the plagioclase laths ( 1-5 $\mu \mathrm{m}$ wide) means some overlap with other mesostasis phases is difficult to avoid. Hence, we cannot be sure that the analyses are not influenced by analytical artefacts. However, TEM EDS estimated up to 0.5 wt. \% FeO and 0.2 wt. $\% \mathrm{MgO}$ in Ch28 zoned plagioclase (Fig. 4), values in the range of those measured by EPMA for Ch28. This suggests that at least some of the $\mathrm{FeO}$ and $\mathrm{MgO}$ measured by EMPA resides in plagioclase.

\section{Bulk chondrule composition and modal mineralogy}

Bulk silicate compositions of selected chondrules measured using quantitative EPMA maps are tabulated in Table 2. The oxide maps used to determine the bulk compositions are illustrated in Fig. S1. The data show a clear trend of increasing An content in plagioclase with increasing bulk Mg\#. The bulk $\mathrm{Na} / \mathrm{Al}$ ratio decreases with increasing An content (1.1-0.1) in the plagioclase, but the $\mathrm{Ca} / \mathrm{Al}$ ratio remains constant across the four chondrules (1.4-1.5). $\mathrm{K}_{2} \mathrm{O}$ is enriched in the type II chondrule $\mathrm{Ch} 3$ (0.13 wt.\%) relative to the other three chondrules that have relatively constant, and low, $\mathrm{K}_{2} \mathrm{O}$ abundances $(0.07-0.08$ wt.\%). Bulk $\mathrm{Cr}_{2} \mathrm{O}_{3}$ is depleted in the $\mathrm{BO}$ chondrule $\mathrm{Ch} 36(0.25 \mathrm{wt} . \%)$ relative to the other three chondrules that are similar in $\mathrm{Cr}_{2} \mathrm{O}_{3}$ content $(0.63-0.71 \mathrm{wt} . \%)$.

The modal silicate mineralogies of the chondrules (Table 2) were estimated from the EPMA maps and are illustrated as mineral maps in Fig. S1. Ch3 is a POP chondrule dominated by olivine (63 vol.\%) and containing approximately equal amounts of low-Ca pyroxene and Ca-rich pyroxene (13 vol.\% and 14 vol. $\%$, respectively), and 10 vol.\% mesostasis. The measured mesostasis abundance includes plagioclase, glass, and small amounts of Ca-rich pyroxene. Ch23 and Ch20 are similar with 27 vol.\% and 19 vol.\% olivine, $57 \mathrm{vol} . \%$ and $66 \mathrm{vol} . \%$ low-Ca pyroxene, similar amounts of Ca-rich pyroxene (7 vol.\%), and 9 vol. \% and 8 vol.\% mesostasis, respectively. The BO chondrule Ch36 consists of 66 vol.\% olivine and 32 vol. $\%$ mesostasis. The 2 vol. \% that was measured as Ca-rich pyroxene represents large grains while most of the Ca-rich pyroxene is $\sim 1 \mu \mathrm{m}$ in size (Fig. 2e) and is included in the reported mesostasis abundance.

\section{$\underline{\text { Discussion }}$}

Primary chondrule minerals contain important information about the physical and chemical conditions during chondrule formation. They can provide information about the timing of the chondrule forming events through relative radiogenic chronometers (e.g., Al-Mg dating), and about cooling rates through petrologic studies. Characterizing primary minerals is also important for revealing the effects of secondary processes. Because these processes alter the chemistry and mineralogy of chondrules, well characterized primary minerals are important for interpreting the effects of thermal metamorphism and metasomatism.

While the presence of primary plagioclase has been noted in OC chondrules before (e.g., Grossman and Brearley 2005; Huss et al. 2001; Russell et al. 2000), its petrography and relationship to bulk chondrule composition have not been studied in detail. In the discussion that follows, we will show that primary plagioclase nucleated and grew as an igneous phase during chondrule cooling, discuss the conditions under which it formed, and consider the implications for chondrule formation including cooling rates and nebular environment. We will also show how secondary features in plagioclase indicate parent body alteration and discuss why an accurate chondrule chronology depends on detailed investigations of chondrule mineralogy.

\section{Primary igneous plagioclase}


Although plagioclase is not thought of as a common primary mineral in OC chondrules, we have shown that it is relatively abundant. Brearley and Jones (1998) did not mention plagioclase in their review of chondrules in type 3 OC. However, anorthite has been noted in Al-rich OC chondrules (Huss et al. 2001; Russell et al. 2000), used largely for Al-Mg chronology, and crystalline albite was seen in a Semarkona chondrule (Grossman and Brearley 2005). It is important first to show that the plagioclase within these chondrules is a primary igneous phase, so that we can use it to understand chondrule formation and the environment in which chondrules were formed.

\section{Feldspar as an igneous phase}

Mineral textures can be used to illustrate the igneous nature of plagioclase in Semarkona chondrules. The plagioclase grains we observe are smooth laths, regardless of their composition (Figs. $2 \mathrm{~b}, \mathrm{c}, \mathrm{e}, 3 \mathrm{~b}, \mathrm{~d}, \mathrm{f})$, consistent with an igneous origin. In contrast, plagioclase that crystallizes from devitrified mesostasis glass is extremely fine grained in the lower petrologic types and does not display a lath-like morphology (Huss et al. 2006). The morphology of plagioclase in Ch3 (Fig. 2b) is similar to fan spherulites, indicating rapid growth with high degrees of undercooling (Corrigan 1982; Lofgren 1974). Albitic laths such as these are common in the outer portions of albite-bearing chondrules. An external nucleation agent, such as nebular dust impinging on the outside of the chondrule, could have helped the plagioclase to nucleate and, combined with undercooling, grow rapidly as the textures indicate. In a similar manner, Connolly and Hewins (1995) were able to experimentally reproduce a variety of chondrule textures by puffing dust onto the surface of molten chondrule droplets to induce nucleation. Although these experiments did not produce plagioclase, it is a reasonable mechanism for producing the albite textures we observe here.

Another way to assess whether the plagioclase in Semarkona chondrules is a primary phase is to look at the bulk compositions of the chondrules in which it is found. A relationship between plagioclase composition and bulk chondrule composition is expected for growth of plagioclase from the melt. As discussed above, the anorthite content in chondrule plagioclase is directly related to the bulk composition of the chondrule: increasing atomic $\mathrm{Mg} \#$ from 78 to 98 in the bulk chondrule corresponds to average plagioclase compositions varying from $\mathrm{An}_{2}$ to $\mathrm{An}_{99}$, an increase in bulk chondrule abundances of refractory elements $\mathrm{Al}$ and $\mathrm{Ca}$, and a decrease in the volatile element $\mathrm{Na}$ (Table 2). Because the $\mathrm{Ca} / \mathrm{Al}$ ratio is constant across the four measured chondrules, the composition of the plagioclase seems tied to the bulk $\mathrm{Na}$ abundance and $\mathrm{Na} / \mathrm{Al}$ ratio, which in turn is inversely correlated with $\mathrm{Mg \#}$, as has been shown previously Grossman and Wasson (1983).

We can use bulk chondrule and plagioclase compositions to provide upper limits on the temperatures at which the plagioclase formed. However, as we discuss further below, plagioclase and mesostasis glass in some of these chondrules have been affected by aqueous alteration, although the major phases (olivine and pyroxene) appear unaffected. Because plagioclase and mesostasis glass are rich in $\mathrm{Na}$, $\mathrm{Ca}, \mathrm{Al}$, and $\mathrm{Si}$, these elements are likely to differ slightly in the bulk silicate composition we measured when compared to the fresh, unaltered chondrule. For this discussion, we assume that the measured bulk silicate compositions are the original igneous compositions.

We used the thermodynamic model rhyolite-MELTS (Ghiorso and Gualda 2015; Gualda et al. 2012) to model the equilibrium crystallization of the bulk compositions listed in Table 2 . We used rhyolite-MELTS instead of the classic MELTS package because of the increased computational stability added to rhyolite-MELTS. The calibration for $\mathrm{low}-\mathrm{SiO}_{2}$ compositions, relevant to the bulk composition of Semarkona chondrules, is the same for the two programs. Chondrule compositions were cooled from the calculated liquidus temperature (Table 2), in $1{ }^{\circ} \mathrm{C}$ increments, at a constant 1 bar pressure, and kept at a constant $f \mathrm{O}_{2}$ along the IW buffer.

The results are illustrated in Fig. 6. Lines show the equilibrium plagioclase composition predicted to crystallize for each bulk chondrule composition. Crosses indicate the measured plagioclase composition and corresponding equilibrium crystallization temperature. For Ch36, the cross is not on the line because the measured anorthite composition $\left(\mathrm{An}_{99}\right)$ was not produced during the modeled plagioclase crystallization: this will be discussed below. Circles indicate the point at which Ca-rich pyroxene 
becomes stable. For each chondrule, the range of plagioclase compositions predicted to crystallize from the bulk composition is close to the measured plagioclase composition from those chondrules: more anorthitic chondrules (Ch36 and Ch20) have plagioclase compositions closer to the first compositions to crystallize, whereas the more albitic chondrules (Ch23 and $\mathrm{Ch} 3)$ are closer to the final compositions to crystallize.

Rhyolite-MELTS simulates batch crystallization under equilibrium conditions, but the rapid cooling experienced by chondrules means that equilibrium conditions were unlikely during crystallization. In fact, due to the extremely slow rate of $\mathrm{Si}-\mathrm{Al}$ interdiffusion, it is unlikely that any feldspar truly grows under equilibrium conditions (Brown and Parsons 1994). However, using rhyoliteMELTS to look at the equilibrium plagioclase compositions is instructive to understand the expected plagioclase compositions and to provide upper limits for formation temperatures. These temperatures are $1197{ }^{\circ} \mathrm{C}, 1098^{\circ} \mathrm{C}$, and $792{ }^{\circ} \mathrm{C}$ for $\mathrm{Ch} 20$, Ch23, and Ch3, respectively.

The measured plagioclase composition in $\mathrm{Ch} 36$ has a greater anorthite content $\left(\mathrm{An}_{99}\right)$ than the most anorthitic composition predicted by the rhyolite-MELTS model ( $\left.\mathrm{An}_{93}\right)$. This puts an upper limit for the crystallization temperature for this composition of $>1260{ }^{\circ} \mathrm{C}$, the temperature at which rhyoliteMELTS nucleated plagioclase. We can also consider this chondrule within the ternary Fo-Di-An system in order to provide a better constraint on the upper limit of the plagioclase crystallization temperature. Forsterite, diopside, and anorthite are the three major phases present within this chondrule and their compositions are close to the $\mathrm{Mg}$-free and $\mathrm{Na}$-free endmembers of the system. We projected the bulk composition measured for $\mathrm{Ch} 36$ onto the Fo-Di-An ternary resulting in a relative composition of 70,8 , and $22 \mathrm{wt} . \%$ Fo, Di, and An, respectively, and close to the measured modal mineral abundances (Table 2). Under equilibrium crystallization conditions, the melt composition, which begins in the Fo primary field, intersects the Fo-An join around $1317^{\circ} \mathrm{C}$ (Osborn and Tait 1952), consistent with the rhyoliteMELTS estimate of $>1260{ }^{\circ} \mathrm{C}$. Hence, $1317{ }^{\circ} \mathrm{C}$ is the temperature used to indicate the plagioclase crystallization temperature for Ch36 on Fig. 6.

Figure 6 also shows the expected relative timing of plagioclase and Ca-rich pyroxene during equilibrium crystallization. Textures showing the relative timing of plagioclase and Ca-rich pyroxene crystallization are a further indicator that plagioclase is primary. Ca-rich pyroxene is often one of the last silicate phases to crystallize in chondrules and it nucleates off the existing phenocrysts of olivine and lowCa pyroxene (e.g., red in the phase maps in Fig. S1). The temperature at which Ca-rich pyroxene becomes stable is relatively insensitive to bulk composition (1055-1225 ${ }^{\circ} \mathrm{C}$, Fig. 6). Because the crystallization temperature of plagioclase is strongly dependent on its composition, we would expect albitic plagioclase to crystallize after Ca-rich pyroxene and anorthitic plagioclase to crystallize before Ca-rich pyroxene but after low-Ca pyroxene. Ch3, Ch28, and $\mathrm{Ch} 23$ have albitic plagioclase compositions and the plagioclase is interstitial to the Ca-rich pyroxene growth (Figs. 2b,c, 3b,d). Ch20, with an intermediate plagioclase composition $\left(\mathrm{An}_{66}\right)$, has plagioclase intergrown with Ca-rich pyroxene (Fig. 3f): Ca-rich pyroxene appears to have nucleated first but continued to grow during plagioclase crystallization. Ch36 has an anorthitic plagioclase composition $\left(\mathrm{An}_{99}\right)$ and $\mathrm{Ca}$-rich pyroxene is present between plagioclase laths (Fig. 2e). Hence, despite the undercooling discussed above, our observations are broadly consistent with the equilibrium model.

Overall, the plagioclase textures, the dependence of plagioclase composition on bulk chondrule composition, the similarities between measured and modeled plagioclase compositions, and the relative timing of crystallization of the plagioclase and Ca-rich pyroxene provide evidence that the plagioclase in these chondrules are primary igneous phases. Rhyolite-MELTS predicts a wide range in the equilibrium crystallization temperatures, $792-1317^{\circ} \mathrm{C}$. These are considered upper limits because of the effects of undercooling. The presence of primary plagioclase in chondrules has implications for chondrule formation that will be explored in the following section.

Implications for chondrule formation and chondrule forming conditions in the solar nebula

Chondrules are the most abundant constituent of the most common type of meteor ite in our collections. Understanding chondrule formation is vital for understanding of what appears to have been a 
ubiquitous process (or set of processes) in the solar nebula (Connolly and Jones 2016). However, the myriad petrologic and experimental constraints provided by chondrule chemistry and mineralogy have not yet stemmed the proliferation of chondrule formation models (Connolly and Desch 2004; Connolly and Jones 2016). Most of these constraints are based on the high-temperature primary minerals olivine and low-Ca pyroxene. Because plagioclase crystallizes at a lower temperature, it can put further constraints on the physical conditions and environment in which chondrules formed.

We observe a wide range of plagioclase compositions $\left(\mathrm{An}_{37}-\mathrm{An}_{100}\right)$ in $\mathrm{FeO}$-poor chondrules. Plagioclase has not previously been recognized in Type I porphyritic chondrules in OCs (Brearley and Jones 1998), but it has been noted as a common phase in Al-rich OC chondrules (Huss et al. 2001; Russell et al. 2000). Plagioclase in Al-rich chondrules has a range of compositions $\left(\mathrm{An}_{70}-\mathrm{An}_{100}\right)$ and is commonly $\geq \mathrm{An}_{90}$ (Huss et al. 2001). Aluminum-rich chondrules have a close affinity to Ca-Al-rich inclusions that are anorthite-bearing. Anorthite has also been described in Type I chondrules in various CCs (Brearley and Jones 1998). Approximately 10\% of Type I chondrules in CO chondrites contain anorthite (Jones 1997; Wick and Jones 2012). Type I chondrules are the dominant chondrule type in CO chondrites, comprising $\sim 85 \%$ of all chondrules compared to only $\sim 20 \%$ of OC chondrules (Jones 2012). The implications of anorthite-bearing Type I chondrules in CO chondrites were explored experimentally by Wick and Jones (2012). They melted a Type I chondrule-like composition at $1500-1600{ }^{\circ} \mathrm{C}$ and cooled the chondrules in stages at rates between $1{ }^{\circ} \mathrm{C}$ and $25^{\circ} \mathrm{C}$ per hour. They found that only the slowest cooling rate $\left(1^{\circ} \mathrm{C} /\right.$ hour in the final cooling stage from $\left.1000-800^{\circ} \mathrm{C}\right)$ could nucleate anorthitic plagioclase. All experiments with faster cooling rates produced glass instead of crystalline plagioclase.

We observed Na-rich plagioclase $\left(\mathrm{An}_{2}-\mathrm{An}_{32}\right)$ in $\mathrm{FeO}$-rich chondrules in Semarkona, which has not been widely recognized before (Brearley and Jones 1998; Jones 1990, 1996). This is not surprising due to the fine scale of the plagioclase laths observed in the chondrules of this study (e.g., Fig. 2b). Grossman and Brearley (2005) identified crystalline albite in Semarkona chondrules through TEM analysis. The recent availability of high resolution FEG-SEMs has allowed for more detailed petrologic studies of chondrules, revealing mineral phases and textures overlooked in previous studies.

The presence of plagioclase in Type II chondrules can also provide constraints on their cooling rates. Rocha and Jones (2012) used the inferred absence of plagioclase in Type IIA OC chondrules to experimentally constrain cooling rates in these chondrules. Using a relatively rapid constant cooling rate, $30{ }^{\circ} \mathrm{C} /$ hour, they reproduced plagioclase-free Type IIA textures. However, by reducing the final cooling rate to $1{ }^{\circ} \mathrm{C} /$ hour $\left(950-900{ }^{\circ} \mathrm{C}\right)$ they crystallized plagioclase, but only when a Type IIAB-like texture developed. This plagioclase had a composition of $\mathrm{An}_{97}$, closer to the composition expected in the Type I chondrules, which was the result of Na loss during the experiment. Because of the low Na content, these experiments are not perfectly analogous to the albite-bearing Type II chondrules we observe in Semarkona. Nucleation of alkali feldspar in anhydrous crystallization experiments is known to be extremely difficult (Smith and Brown 1988), and this is supported by the absence of plagioclase in typical chondrule analogue experiments that are cooled at rapid rates. However, the presence of albite growing from the chondrule exterior suggests that it might have been nucleated by dust impinging on the chondrule exterior after the melt was supercooled well below the equilibrium crystallization temperature (Connolly and Hewins 1995).

Baecker et al. (2017) uses zoning in low-Ca pyroxene from FeO-rich chondrules, like the albitebearing $\mathrm{Ch} 3$ (Fig. 2b), to argue for multiple heating events and rapid cooling. In their model, each heating event re-melted the chondrule mesostasis glass, formed successive overgrowth layers on the low-Ca pyroxene grains, and then cooled rapidly. However, Jones (1996) describes the same zoning in low-Ca pyroxene as oscillatory zoning and attributes it to formation through disequilibrium kinetic effects at the mineral/melt boundary. Allègre et al. (1981) argues that oscillatory zoning in plagioclase only occurs during slow cooling to account for a near absence of such zoning in lab-grown plagioclase. The presence of albite in $\mathrm{FeO}$-rich chondrules, the nucleation of which requires slow cooling rates, favors the interpretation of Jones (1996) that zoning in low-Ca pyroxene is oscillatory and not an overgrowth texture. Furthermore, Ohnensetter and Brown (1992) estimated the cooling rates inferred for oscillatoryzoned pyroxenes in a terrestrial boninite dyke to be $1-5^{\circ} \mathrm{C} /$ hour, in agreement with the cooling rates that 
nucleated plagioclase in the chondrule analog experiments (Rocha and Jones 2012; Wick and Jones 2012).

The presence of volatile elements, such as $\mathrm{Na}$ and $\mathrm{K}$, in chondrules is a conundrum for chondrule forming scenarios. These elements should have rapidly diffused out of molten chondrules at the high temperatures and low ambient nebular pressure thought to be present during their formation ( $\mathrm{Yu}$ and Hewins 1998; Yu et al. 2003) and then they could have recondensed back onto the chondrule during cooling (Lewis et al. 1993). Models show that the $\mathrm{Na}$ and $\mathrm{K}$ lost at liquidus temperatures can condense on the molten chondrule near the end of crystallization if the chondrule forming region had a dust to gas ratio much greater than solar (Ebel and Grossman 2000), resulting in high partial pressures of $\mathrm{Na}$ and $\mathrm{K}$ (Hewins et al. 2005). However, measurements of $\mathrm{Na}$ zoning in olivine are consistent with constant bulk $\mathrm{Na}$ during olivine crystallization (Alexander et al. 2008) suggesting high solid densities and Na retention even during the relatively slow cooling rates necessary to nucleate plagioclase. The presence of albite in chondrules supports the model of a Na-enriched atmosphere in the chondrule forming region(s) allowing for $\mathrm{Na}$ to be retained within the chondrules.

\section{Secondary alteration of chondrule glass and feldspar}

Semarkona has undergone a limited degree of aqueous alteration. Evidence for this includes the presence of phyllosilicates (Alexander et al. 1989; Grossman and Brearley 2005; Hutchison et al. 1987), carbonates (Alexander et al. 2015; Hutchison et al. 1987), carbide-magnetite assemblages (Krot et al. 1997), sulfide-magnetite assemblages (Huss 1979), altered chondrules (Hutchison et al. 1987; Rubin 2013), bleached chondrules (Grossman et al. 2000), and zoned chondrules (Grossman et al. 2002). Our observations of the dissolution of mesostasis glass, the presence of phyllosilicates in chondrules, and the alteration of primary igneous feldspar add to these arguments for fluid activity. Understanding whether feldspar grains are pristine or altered has important implications for early solar system chronology as determined by Al-Mg systematics.

\section{Evidence for the presence of fluids in chondrule glass}

Nearly all the plagioclase-bearing chondrules we examined show at least some porosity between plagioclase laths that we interpret as the dissolution of chondrule mesostasis glass by an aqueous fluid. The chondrules in Fig. 3 (Ch28, Ch23, and Ch20) show extensive dissolution of glass, while $\mathrm{Ch} 3$ and Ch36 in Fig. 2 have smaller patches of dissolved glass, typically along the chondrule perimeter (e.g., Fig. 2e). Large pores (>50 $\mu \mathrm{m}$ in diameter) are also present in several chondrules (e.g., Ch28) and are easily visible as black spots within chondrules on the thin section BSE map (Fig. 1). Ch28 has very large pores (up to $370 \mu \mathrm{m}$ in diameter, Fig. 3a) although it is not clear if the large pores are inherent to the sample or a product of the sample preparation process (i.e., plucked metal grains). The FIB section of the zoned albite in Ch28 (Fig. 4a) shows pores between plagioclase laths as small as $20 \mathrm{~nm}$.

Grossman et al. (2000) conducted a detailed study of bleached chondrules in Semarkona: these are fine-grained, cryptocrystalline and radiating pyroxene chondrules that have zones of dissolved mesostasis along their outer edges. They showed that these chondrules were affected by a parent body alteration process that preferentially dissolved the mesostasis without affecting the adjacent pyroxene. They noted that the mesostasis in porphyritic chondrules did not appear to be affected by the alteration process in the same way as the fine-grained chondrules and attributed this to either differences in mesostasis compositions or grain sizes between the various chondrule types.

The glass in cryptocrystalline and radiating pyroxene chondrules contains a high percentage of normative albite, whereas the glass in Type I chondrules is anorthitic and in Type II chondrules is rich in normative quartz (Grossman et al. 2000). However, we have shown that all the porphyritic chondrules we studied have varying amounts of dissolved mesostasis glass, some quite extensive (e.g., Ch23, Fig. 3d). This implies that mesostasis composition cannot be the determining factor for glass dissolution. Grossman et al. (2000) also pointed out that uniformly fine-grained chondrules contain more grain boundaries than the relatively coarse-grained porphyritic chondrules and thus more avenues for fluid to flow into and out of the chondrules from the matrix. In porphyritic chondrules, radial bleaching zones, 
like those seen in uniformly fine-grained chondrules, are less likely to occur due to heterogeneous distributions of grain sizes and regions of mesostasis.

Phyllosilicates have been identified in Semarkona matrix and, like the bleached chondrules, imply alteration of primary phases by an aqueous fluid (Alexander et al. 1989; Hutchison et al. 1987). Hutchison et al. (1987) noted hydrous alteration of chondrule glass and Rubin (2013) illustrated an alteration front in the glass of a BO chondrule. Grossman et al. (2000) showed that bleached chondrules contain phyllosilicates that are compositionally distinct from those found in the matrix, and argued that they formed by the alteration of chondrule glass in the same event that dissolved some of the mesostasis glass. We observe phyllosilicates in place of mesostasis glass in Ch28 (Figs. 3b,4a) and Ch26 and in very minor amounts in Ch3 (Fig. 2c) that likely formed in a similar way. In these chondrules, the mesostasis glass between feldspar laths has both been dissolved, resulting in pores, and replaced by phyllosilicates (Fig. $4 a)$.

Dobrică and Brearley (2016) investigated a fine-grained matrix inclusion in a Semarkona POP chondrule. They showed porosity associated with glass altered to phyllosilicates, like what we describe above. Clearly this mode of fluid alteration was widespread in Semarkona and resulted in the alteration of a range of chondrule types (and matrix), not just fine-grained, bleached chondrules. Grossman et al. (2000) noted that bleached chondrules were present in nearly all petrologic types and suggested that all OCs underwent fluid alteration of this sort before the onset of thermal metamorphism. It would be reasonable to extend this model to porphyritic chondrules as well.

\section{Secondary alteration of primary plagioclase}

Feldspar is nearly homogeneous in chondrules that either do not show the mesostasis alteration described above, or are minimally altered (e.g., Ch3 and Ch36, Table 1, Fig. 5). However, chondrules with extensively dissolved mesostasis glass or the presence of phyllosilicates show much more variation in their feldspar compositions. This variation in chondrule-wide plagioclase compositions is illustrated in Fig. 5. The vertical error bars represent one standard deviation about the mean An content measured for each chondrule and can be over $5 \mathrm{~mol}$. \% An. Variation is also seen within individual plagioclase laths that are present adjacent to regions of alteration. Plagioclase in Ch28 (Fig. 3b,4) and Ch23 (Fig. 3d) is irregularly zoned subparallel to the regions of dissolved chondrule mesostasis glass and, in the case of $\mathrm{Ch} 28$, glass alteration to phyllosilicates.

A FIB section (Fig. 4a) was prepared of a zoned plagioclase region in Ch28 (white line in Fig. 3b) to explore the zoning in more detail. A HAADF image of a representative area is shown in Fig. $4 \mathrm{~b}$ and the corresponding EDS $\mathrm{Ca} \mathrm{K} \alpha$ map is shown in Fig. 5c. Zoning is observed in $\mathrm{Al}, \mathrm{Na}$, and $\mathrm{Ca}$, but $\mathrm{Ca}$ shows the most heterogeneity and is likely responsible for the zoned appearance of the plagioclase grains in the BSE image (Fig. 3b). Calcium is variably zoned and predominantly absent from the outer 100-150 nm of the $\sim 650 \mathrm{~nm}$ wide laths. There also appear to be enrichments of $\mathrm{Ca}$ on the border of the low-Ca outer zone as well as in the phyllosilicates themselves.

A similar zoning profile (Ca-rich core, Na-rich rim) is expected from normal igneous zoning, but several features are inconsistent with an igneous origin for the zoning in these grains. First, the Ca zoning shows considerable variation along the long axis of the grain and is not symmetric about the core (Fig. $5 b)$. Second, the degree of Ca zoning appears to reflect proximity to areas of dissolved mesostasis glass or phyllosilicate growth. Third, plagioclase in chondrules from which the glass has not been dissolved does not show similar compositional zoning or widespread heterogeneity. Fourth, Ch3 has dominantly homogeneous albite (Fig. 2b) but zoned albite is only seen in regions of alteration (Fig. 2c). Clearly, plagioclase zoning in these chondrules is due to secondary processes and is not attributable to primary igneous growth.

Closely related to our observations of Ca-zoning in altered primary plagioclase, calcic plagioclase is replaced by more sodic compositions as the result of Na-metasomatism during metamorphism in higher petrologic type chondrites. In petrologic types 4 and 5, anorthitic plagioclase is affected by albitization, creating rims of nearly pure albite (Kovach and Jones 2010; Lewis and Jones 2016). Progressive metamorphism equilibrates plagioclase compositions to a uniform $\sim \mathrm{An}_{11}$ by petrologic type 6 (Kovach 
and Jones 2010; Van Schmus and Wood 1967). The presence of alteration in Semarkona plagioclase grains possibly represents the first step in the feldspar equilibration process that was experienced in varying amounts by all ordinary chondrites.

\section{Characteristics of the fluid environment}

The alteration of mesostasis glass and primary plagioclase in Semarkona chondrules strongly argues for open system behavior between chondrules and the matrix and the transport of material into and out of chondrules by an aqueous fluid. The characteristics of this process are described at length by Grossman et al. $(2000,2002)$ in their studies of bleached and zoned chondrules and our observations generally agree with their conclusions. The bleaching process, removal of chondrule glass, results in depletions of $\mathrm{Na}, \mathrm{K}, \mathrm{Sr}, \mathrm{Si}$, and $\mathrm{Al}$ from the outer regions of the affected chondrules. The hydration and alteration of the remaining glass to phyllosilicates is associated with the introduction of $\mathrm{Fe}$, Ni, halogens, and water (Grossman et al. 2000).

Complementary to the bleached chondrules, chondrule mesostases in many low-FeO chondrules display concentric chemical zoning with enrichments in $\mathrm{Na}$, $\mathrm{K}$, other moderately volatile elements, and water and depletions in $\mathrm{Ca}, \mathrm{Cr}$, and $\mathrm{Ti}$ (Grossman et al. 2002). We observe a similar pattern in the homogeneous anorthite-bearing BO chondrule Ch36 in which the CL image shows zoning of mesostasis glass from pale yellow in the center to bright yellow along the rim (Fig. 2f), a signature of Na enrichment in the rim noted by Grossman et al. (2002). The transfer of these elements by an aqueous fluid did not result in the devitrification of the chondrule glass nor the extensive leaching seen in bleached chondrules (Grossman et al. 2002).

Water in chondrites is commonly assumed to be derived from ices present during accretion. The ices melt and water flows though the permeable matrix and along grain boundaries in order to redistribute a variety of water soluble elements. However, the conditions of glass and plagioclase alteration were not severe enough to affect olivine or pyroxene. Grossman et al. (2000) argued that the alteration temperature may have been less than $100^{\circ} \mathrm{C}$ based on similarities to $\mathrm{CC}$ alteration assemblages. This is less than the maximum temperature of $260^{\circ} \mathrm{C}$ estimated by Alexander et al. (1989) based on the stability of the phyllosilicates found in the matrix. The dissolution of $\mathrm{Si}$ from the mesostasis glass implies a high $\mathrm{pH}$ (Alexander et al. 1954) and is consistent with the presence of calcite in Semarkona (Alexander et al. 2015). Incomplete and inconsistent alteration between chondrules, even of similar chemical compositions, implies a low water-rock ratio, the effects of which may be exaggerated by limited chondrule permeability.

Overall, the degree of aqueous alteration observed in Semarkona chondrules is not consistent between chondrules, from grain to grain within a chondrule, or within individual mineral grains. Limited fluid availability, variation in fluid permeability of the matrix and chondrules, and the wide variety of chondrule mesostasis compositions, some of which were more easily altered than others, likely gave rise to the complex pattern of alteration we now see.

\section{Implication for Al-Mg dating of Semarkona chondrules and solar system chronology}

High resolution chronology using short-lived radioactive isotopes is a powerful tool for understanding the relative order of events during a very important time in the history of the early solar system. The Al-Mg system is used for dating chondrules because they contain significant amounts of Al. Bulk chondrule compositions typically contain 1-5 wt. $\% \mathrm{Al}_{2} \mathrm{O}_{3}$, but can be $>10$ wt. $\% \mathrm{Al}_{2} \mathrm{O}_{3}$ in Al-rich chondrules (Brearley and Jones 1998). Mesostasis glass and plagioclase are major hosts of $\mathrm{Al}$ in chondrules, although minor amounts are also present in Ca-rich pyroxene and spinel. As shown above, chondrule mesostasis glass in a significant number of Semarkona chondrules shows evidence of being dissolved and/or altered to phyllosilicates. Plagioclase also shows evidence for alteration through $\mathrm{Na}-\mathrm{Ca}$ and $\mathrm{Al}-\mathrm{Si}$ exchange. Therefore, it is important to evaluate what effects alteration may have had on measured Al-Mg ages.

Chondrules within Semarkona have been dated using Al-Mg systematics by a number of workers (Hutcheon and Hutchison 1989; Kita et al. 2000; Mishra and Goswami 2014; Mishra et al. 2010; 
Mostefaoui et al. 2002; Rudraswami et al. 2008; Russell et al. 1997; Villeneuve et al. 2009). These studies report ages that range between $0.76 \mathrm{Ma}$ and 3.07 Ma after CAI formation, a span of 2.3 million years. The wide range of ages has been explained as the period during which chondrules were formed (e.g., Villeneuve et al. 2009). However, the reported errors in many of the Semarkona measurements are broad (0.5-1 Ma) implying that the isochrons were defined through considerable scatter. Alexander and Ebel (2012) showed that the errors associated with Al-Mg systematics are consistent with a single formation age and that additional scatter is due to disturbance during parent body processing. Kita and Ushikubo (2012) also conclude that chondrules in each chondrite group formed over a short period of time, including those in Semarkona, based on their review of existing Al-Mg data.

Since we observe ubiquitous aqueous alteration of Al-bearing phases in Semarkona, we concur that it is likely that the Al-Mg systematics have been inconsistently disturbed by secondary processes on Semarkona's parent asteroid. This disturbance would generate large errors in the measured isochrons or may have reset the Al-Mg system in some chondrules altogether, yielding younger ages. Thus, the reported chondrule formation ages in Semarkona may record a combination of secondary aqueous alteration and primary chondrule formation. Furthermore, thermal modeling of OC asteroids, based on internal heating from the decay of ${ }^{26} \mathrm{Al}$, is consistent with accretion 2.05-2.25 Ma after CAI formation (Blackburn et al. 2017), suggesting that chondrule ages younger than this were disturbed or reset.

In additional support of this argument, aqueous alteration in carbonaceous chondrites, measured by Mn-Cr dating of carbonates (Fujiya et al. 2012, 2013; Hoppe et al. 2007; Jilly et al. 2014; Lee et al. 2012; de Leuw et al. 2009; Petitat et al. 2011), overlaps the formation period for Semarkona chondrules (between $0.4 \mathrm{Ma}$ and 6.2 Ma after CAIs). However, it is important to note that the history of low temperature secondary processes on the ordinary and carbonaceous chondrite parent bodies are not necessarily identical.

These conclusions reinforce the need for high-resolution petrographic studies of chondritic materials prior to utilizing high precision analytical techniques on what is only assumed to be unaltered nebular material. Careful consideration needs to be made of the state of the major, and possibly minor, phases relevant to the technique. For Al-Mg, dissolution of chondrule mesostasis glass, alteration of primary plagioclase, formation of secondary minerals, like phyllosilicates, and zoning of volatile elements like $\mathrm{Na}$ within the chondrule glass would be reason to suspect a compromised system. For example, Mostefaoui et al. (2002) found a correlation between younger Al-Mg age and increasing bulk Na, Mn, and $\mathrm{Cr}$ abundances relative to $\mathrm{Mg}$. These are elements shown by Grossman et al. (2002) to be zoned in Semarkona chondrules, the result of aqueous alteration.

\section{$\underline{\text { Summary \& Conclusions }}$}

We conducted a detailed study of plagioclase in Semarkona chondrules to characterize this mineral as a primary igneous phase and to understand how it might be affected by secondary processes such as aqueous alteration and thermal metamorphism. We found plagioclase with a wide range of compositions $\left(\mathrm{An}_{2}-\mathrm{An}_{99}\right)$ was present within $18 \%$ of the chondrules in the thin section we studied. The plagioclase grains have lath-like morphologies consistent with growth from a melt. Plagioclase compositions are also directly related to the bulk composition of the chondrule: plagioclase in $\mathrm{FeO}$-poor chondrules is more Ca-rich, and plagioclase in FeO-rich chondrules is more Na-rich. Experimental investigations into plagioclase growth in chondrules suggest plagioclase-bearing chondrules cooled extremely slowly as they approach the solidus $\left(1{ }^{\circ} \mathrm{C} /\right.$ hour for anorthitic plagioclase $)$, so these slow cooling rates apparently apply to a high proportion of OC chondrules.

The aqueous alteration that is known to affect Semarkona mineralogy has also altered the texture and composition of primary plagioclase in many chondrules. This has led to zoning of $\mathrm{Na}$ and $\mathrm{Ca}$ in plagioclase grains and a general spread in the plagioclase compositions within altered chondrules. These effects are seen in association with the development of porosity from the dissolution of chondrule mesostasis glass and the alteration of glass to phyllosilicates. These features have been observed previously in bleached and zoned chondrules in Semarkona and imply a low temperature, high $\mathrm{pH}$ fluid at a low water-rock ratio (Alexander et al. 1954; Grossman et al. 2000, 2002). The pervasive nature of 
alteration calls into question the reliability of Al-Mg systematics for understanding the chronology of chondrule formation, in cases where chondrules have undergone alteration of mesostasis glass and plagioclase.

\section{Acknowledgements}

We would like to thank C. Alexander and A. Rubin for helpful reviews, Mike Spilde for his help with the microprobe, Elena Dobrică for her assistance with TEM sample preparation, and Adrian Brearley for useful discussions. Work was carried out at the Electron Microbeam Analysis Facility, Department of Earth and Planetary Sciences and Institute of Meteoritics, University of New Mexico and at the

Williamson Research Centre, University of Manchester. J. Lewis acknowledges support from the KelleySilver Foundation, University of New Mexico, the New Mexico Space Grant Consortium, and is grateful to the University of Manchester for sponsoring his visit to the School of Earth and Environmental Sciences. The work was partially funded by NASA grant NNX12AH61G (P.I. R. Jones).

\section{References}

Alexander G. B., Heston W. M., and Iler R. K. 1954. The solubility of amorphous silica in water. The Journal of Physical Chemistry 58:453-455.

Alexander C. M. O., Barber D. J., and Hutchison R. 1989. The microstructure of Semarkona and Bishunpur. Geochimica et Cosmochimica Acta 53:3045-3057.

Alexander C. M. O'D., Grossman J. N., Ebel D. S., and Ciesla F. J. 2008. The formation conditions of chondrules and chondrites. Science 320:1617-1619.

Alexander C. M. O'D. and Ebel D. S. 2012. Questions, questions: can the contradictions between the petrologic, isotopic, thermodynamic, and astrophysical constraints on chondrule formation be resolved? Meteoritics \& Planetary Science 47:1157-1175.

Alexander C. M. O’D., Bowden R., Fogel M. L., and Howard K. T. 2015. Carbonate abundances and isotopic compositions in chondrites. Meteoritics \& Planetary Science 50:810-833.

Allègre C. J., Provost A., and Jaupart C. 1981. Oscillatory zoning: a pathological case of crystal growth. Nature 294:223.

Baecker B., Rubin A. E., and Wasson J. T. 2017. Secondary melting events in Semarkona chondrules revealed by compositional zoning in low-Ca pyroxene. Geochimica et Cosmochimica Acta 211:256-279.

Blackburn T., Alexander C. M. O’D., Carlson R., and Elkins-Tanton L. T. 2017. The accretion and impact history of the ordinary chondrite parent bodies. Geochimica et Cosmochimica Acta 200:201-217.

Brearley A. J. and Jones R. H. 1998. Chondritic meteorites. In Planetary materials, edited by Papike J. J. pp. 3.1-3.398.

Brown W. L. and Parsons I. 1994. Feldspars in igneous rocks. In Feldspars and their reactions, edited by Parsons I. Dordrecht: Springer Netherlands. pp. 449-499.

Connolly H. C. and Hewins R. H. 1995. Chondrules as products of dust collisions with totally molten droplets within a dust-rich nebular environment: an experimental investigation. Geochimica et Cosmochimica Acta 59:3231-3246.

Connolly H. C. and Desch S. J. 2004. On the origin of the "kleine Kügelchen" called chondrules. Chemie der Erde - Geochemistry 64:95-125.

Connolly H. C. and Jones R. H. 2016. Chondrules: the canonical and noncanonical views. Journal of Geophysical Research: Planets 121:1885-1899.

Corrigan G. 1982. The crystal morphology of plagioclase feldspar produced during isothermal supercooling and constant rate cooling experiments. Mineralogical Magazine 46:433-439.

Dobrică E. and Brearley A. J. 2016. Selective dissolution of plagioclase in Semarkona: low-temperature fluid-solid interactions (abstract \#6228). $79^{\text {th }}$ Annual Meeting of the Meteoritical Society.

Ebel D. S. and Grossman L. 2000. Condensation in dust-enriched systems. Geochimica et Cosmochimica Acta 64:339-366. 
Fujiya W., Sugiura N., Hotta H., Ichimura K., and Sano Y. 2012. Evidence for the late formation of hydrous asteroids from young meteoritic carbonates. Nature Communications 3:627.

Fujiya W., Sugiura N., Sano Y., and Hiyagon H. 2013. Mn-Cr ages of dolomites in CI chondrites and the Tagish Lake ungrouped carbonaceous chondrite. Earth and Planetary Science Letters 362:130142.

Ghiorso M. S. and Gualda G. A. R. 2015. An $\mathrm{H}_{2} \mathrm{O}-\mathrm{CO}_{2}$ mixed fluid saturation model compatible with rhyolite-MELTS. Contributions to Mineralogy and Petrology 169:53.

Grossman J. N. and Wasson J. T. 1983. The compositions of chondrules in unequilibrated chondrites: an evaluation of models for the formation of chondrules and their precursor materials. In Chondrules and their origins, edited by King E. A. pp. 88-121.

Grossman J. N., Alexander C. M. O’D., Wang J., and Brearley A. J. 2000. Bleached chondrules: evidence for widespread aqueous processes on the parent asteroids of ordinary chondrites. Meteoritics \& Planetary Science 35:467-486.

Grossman J. N., Alexander C. M. O’D., Wang J., and Brearley A. J. 2002. Zoned chondrules in Semarkona: evidence for high- and low-temperature processing. Meteoritics \& Planetary Science 37:49-73.

Grossman J. N. and Brearley A. J. 2005. The onset of metamorphism in ordinary and carbonaceous chondrites. Meteoritics \& Planetary Science 40:87-122.

Gualda G. A. R., Ghiorso M. S., Lemons R. V., and Carley T. L. 2012. Rhyolite-MELTS: a modified calibration of MELTS optimized for silica-rich, fluid-bearing magmatic systems. Journal of Petrology 53:875-890.

Hewins R. H., Connolly H. C. Jr., Lofgren G. E., and Libourel G. 2005. Experimental constraints on chondrule formation. In Chondrites and the protoplanetary disk, edited by Krot A. N., Scott E. R. D., and Reipurth B. pp. 286-316.

Hoppe P., MacDougall D., and Lugmair G. W. 2007. High spatial resolution ion microprobe measurements refine chronology of carbonate formation in Orgueil. Meteoritics \& Planetary Science 42:1309-1320.

Huss G. R. 1979. The matrix of unequilibrated ordinary chondrites: implications for the origin and subsequent history of chondrites. Master's thesis, Albuquerque: University of New Mexico.

Huss G. R., MacPherson G. J., Wasserburg G. J., Russell S. S., and Srinivasan G. 2001. Aluminum-26 in calcium-aluminum-rich inclusions and chondrules from unequilibrated ordinary chondrites. Meteoritics \& Planetary Science 36:975-997.

Huss G. R., Rubin A. E., and Grossman J. N. 2006. Thermal metamorphism in chondrites. In Meteorites and the early solar system II, edited by Lauretta D. S. and McSween Jr. H. Y. Tucson, AZ: The University of Arizona Press. pp. 567-586.

Hutcheon I. D., and Hutchison R. 1989. Evidence from the Semarkona ordinary chondrite for ${ }^{26} \mathrm{Al}$ heating of small planets. Nature 337:238-241.

Hutchison R., Alexander C. M. O., and Barber D. J. 1987. The Semarkona meteorite: first recorded occurrence of smectite in an ordinary chondrite, and its implications. Geochimica et Cosmochimica Acta 51:1875-1882.

Jilly C. E., Huss G. R., Krot A. N., Nagashima K., Yin Q.-Z., and Sugiura N. 2014. Mn-53-Cr-53 dating of aqueously formed carbonates in the CM2 lithology of the Sutter's Mill carbonaceous chondrite. Meteoritics \& Planetary Science 49:2104-2117.

Jones R. H. 1990. Petrology and mineralogy of Type II, FeO-rich chondrules in Semarkona (LL3.0): origin by closed-system fractional crystallization, with evidence for supercooling. Geochimica et Cosmochimica Acta 54:1785-1802.

Jones R. H. 1994. Petrology of FeO-poor, porphyritic pyroxene chondrules in the Semarkona chondrite. Geochimica et Cosmochimica Acta 58:5325-5340.

Jones R. H. 1996. FeO-rich, porphyritic pyroxene chondrules in unequilibrated ordinary chondrites. Geochimica et Cosmochimica Acta 60:3115-3138. 
Jones R. H. 1997. Ubiquitous anorthitic plagioclase in Type I chondrules in CO3 chondrites: implications for chondrule formation and parent body metamorphism (abstract \#5240). 60 ${ }^{\text {th }}$ Annual Meeting of the Meteoritical Society.

Jones R. H. 2012. Petrographic constraints on the diversity of chondrule reservoirs in the protoplanetary disk. Meteoritics \& Planetary Science 47:1176-1190.

Kita N. T., Nagahara H., Togashi S., and Morishita Y. 2000. A short duration of chondrule formation in the solar nebula: evidence from ${ }^{26} \mathrm{Al}$ in Semarkona ferromagnesian chondrules. Geochimica et Cosmochimica Acta 64:3913-3922.

Kita N. T. and Ushikubo T. 2012. Evolution of protoplanetary disk inferred from ${ }^{26} \mathrm{Al}$ chronology of individual chondrules. Meteoritics \& Planetary Science 47:1108-1119.

Kovach H. A. and Jones R. H. 2010. Feldspar in type 4-6 ordinary chondrites: metamorphic processing on the H and LL chondrite parent bodies. Meteoritics \& Planetary Science 45:246-264.

Krot A. N., Zolensky M. E., Wasson J. T., Scott E. R. D., Keil K., and Ohsumi K. 1997. Carbidemagnetite assemblages in type-3 ordinary chondrites. Geochimica et Cosmochimica Acta 61:219237.

Lee M. R., Lindgren P., Sofe M. R., Alexander C. M. O'D., and Wang J. 2012. Extended chronologies of aqueous alteration in the CM2 carbonaceous chondrites: evidence from carbonates in Queen Alexandra Range 93005. Geochimica et Cosmochimica Acta 92:148-169.

de Leuw S., Rubin A. E., Schmitt A. K., and Wasson J. T. 2009. ${ }^{53} \mathrm{Mn}-{ }^{53} \mathrm{Cr}$ systematics of carbonates in $\mathrm{CM}$ chondrites: implications for the timing and duration of aqueous alteration. Geochimica et Cosmochimica Acta 73:7433-7442.

Lewis R. D., Lofgren G. E., Franzen H. F., and Windom K. E. 1993. The effect of Na vapor on the Na content of chondrules. Meteoritics 28:622-628.

Lewis J. A. and Jones R. H. 2016. Phosphate and feldspar mineralogy of equilibrated L chondrites: the record of metasomatism during metamorphism in ordinary chondrite parent bodies. Meteoritics \& Planetary Science 51:1886-1913.

Lofgren G. 1974. An experimental study of plagioclase crystal morphology: isothermal crystallization. American journal of Science 274:243-273.

Mishra R. K., Goswami J. N., Tachibana S., Huss G. R., and Rudraswami N. G. $2010 .{ }^{60} \mathrm{Fe}$ and ${ }^{26} \mathrm{Al}$ in chondrules from unequilibrated chondrites: implications for early solar system processes. The Astrophysical Journal Letters 714:L217.

Mishra R. K. and Goswami J. N. 2014. Fe-Ni and Al-Mg isotope records in UOC chondrules: plausible stellar source of ${ }^{60} \mathrm{Fe}$ and other short-lived nuclides in the early Solar System. Geochimica et Cosmochimica Acta 132:440-457.

Mostefaoui S., Kita N. T., Togashi S., Tachibana S., Nagahara H., and Morishita Y. 2002. The relative formation ages of ferromagnesian chondrules inferred from their initial aluminum-26/aluminum27 ratios. Meteoritics \& Planetary Science 37:421-438.

Ohnensetter D. and Brown W. L. 1992. Overgrowth textures, disequilibrium zoning, and cooling history of a glassy four-pyroxene boninite dyke from New Caledonia. Journal of Petrology 33:231-271.

Osborn E. F. and Tait D. B. 1952. The system diopside-forsterite-anorthite. American Journal of Science 38:413-433.

Petitat M., Marrocchi Y., McKeegan K. D., Mostefaoui S., Meibom A., Zolensky M. E., and Gounelle M. 2011. ${ }^{53} \mathrm{Mn}-{ }^{53} \mathrm{Cr}$ ages of Kaidun carbonates. Meteoritics \& Planetary Science 46:275-283.

Rocha S. E. and Jones R. H. 2012. An experimental study of the conditions of type II chondrule formation in ordinary chondrites (abstract \#2595). 43 ${ }^{\text {rd }}$ Lunar and Planetary Science Conference.

Rubin A. E. 2013. Multiple melting in a four-layered barred-olivine chondrule with compositionally heterogeneous glass from LL3.0 Semarkona. Meteoritics \& Planetary Science 48:445-456.

Rudraswami N. G., Goswami J. N., Chattopadhyay B., Sengupta S. K., and Thapliyal A. P. 2008. ${ }^{26}$ Al records in chondrules from unequilibrated ordinary chondrites: II. duration of chondrule formation and parent body thermal metamorphism. Earth and Planetary Science Letters 274:93102. 
Russell S. S., Huss G. R., MacPherson G. J., and Wasserburg G. J. 1997. Early and late chondrule formation: new constraints for solar nebula chronology from ${ }^{26} \mathrm{Al} /{ }^{27} \mathrm{Al}$ in unequilibrated ordinary chondrites (abstract \#1468). 28 ${ }^{\text {th }}$ Lunar and Planetary Science Conference.

Russell S. S., MacPherson G. J., Leshin L. A., and McKeegan K. D. 2000. ${ }^{16}$ O enrichments in aluminumrich chondrules from ordinary chondrites. Earth and Planetary Science Letters 184:57-74.

Smith J. V. and Brown W. L. 1988. Feldspar minerals: volume 1, crystal structures, physical, chemical, and microtextural properties, $2^{\text {nd }}$ ed. Berlin: Springer. 828. p.

Tenner T. J., Ushikubo T., Nakashima D., Kita N. T., Weisberg M. K., and Kimura M. 2014. Silica excess in anorthitic plagioclase from type 3.00 chondrite chondrules: evidence for retaining primary ${ }^{26} \mathrm{Al}-{ }^{26} \mathrm{Mg}$ systematics (abstract \#1187). 45 ${ }^{\text {th }}$ Lunar and Planetary Science Conference.

Tenner T. J. 2017. Evaluating silica excess in Dominion Range 08006 chondrule plagioclase: comparisons to Yamato 81020 and Acfer 094 chondrule plagioclase (abstract \#6394). 80 ${ }^{\text {th }}$ Annual Meeting of the Meteoritical Society.

Van Schmus W. R. and Wood J. A. 1967. A chemical-petrologic classification for the chondritic meteorites. Geochimica et Cosmochimica Acta 31:747-765.

Villeneuve J., Chaussidon M., and Libourel G. 2009. Homogeneous distribution of ${ }^{26} \mathrm{Al}$ in the solar system from the Mg isotopic composition of chondrules. Science 325:985-988.

Wick M. J. and Jones R. H. 2012. Formation conditions of plagioclase-bearing type I chondrules in CO chondrites: a study of natural samples and experimental analogs. Geochimica et Cosmochimica Acta 98:140-159.

Yu Y. and Hewins R. H. 1998. Transient heating and chondrule formation: evidence from sodium loss in flash heating simulation experiments. Geochimica et Cosmochimica Acta 62:159-172.

Yu Y., Hewins R. H., Alexander C. M. O'D., and Wang J. 2003. Experimental study of evaporation and isotopic mass fractionation of potassium in silicate melts. Geochimica et Cosmochimica Acta 67:773-786. 


\section{Figure Captions}

Fig. 1. BSE mosaic of Semarkona thin section UNM 549. Plagioclase-bearing chondrules are circled in white. Numbered chondrules are referenced in the text, figures, and tables.

Fig. 2. Examples of albite- and anorthite-bearing chondrules with end-member plagioclase compositions. $(\mathrm{a}, \mathrm{b}) \mathrm{BSE}$ images of $\mathrm{Ch} 3$, a Type I POP chondrule with laths of albite $\left(\mathrm{ab}, \mathrm{An}_{2}\right)$ in mesostasis glass $(\mathrm{gl})$ between grains of olivine (ol), low-Ca pyroxene (px), and Ca-rich pyroxene (cpx). Inset in (b) shows CL image of the same region illustrating the bright blue luminescence of albite laths. (c) Region of Ch3 along the rim in which the albite laths are zoned and some of the glass is replaced by phyllosilicates (phy). (d,e) BSE images of Ch36, an FeO-poor BO chondrule with light grey mesostasis (ms) and laths of anorthite (an, $\mathrm{An}_{99}$ ) between the olivine bars. Ca-rich pyroxene and glass occur interstitial to the anorthite. (f) $\mathrm{CL}$ image of the entire chondrule in which the anorthite luminesces light blue and the glass luminesces pale yellow in the center and bright yellow along the rim.

Fig. 3. Examples of chondrules with plagioclase of intermediate composition. Ch28 $(\mathrm{a}, \mathrm{b})$ is a Type II POP chondrule with large voids. Plagioclase $\left(\mathrm{plg}, \mathrm{An}_{10}\right)$ in this chondrule is present as laths that are interstitial to grains olivine (ol), Ca-rich pyroxene (cpx), and minor sulfides (sul). The plagioclase is zoned and pores and phyllosilicates are present between the plagioclase laths. The white line shows the region from which a FIB section was made (see Fig. 4). Ch23 (c,d) is a Type I POP chondrule with plagioclase $\left(\mathrm{An}_{37}\right)$ interstitial to olivine, low-Ca pyroxene ( $\mathrm{px}$ ), and Ca-rich pyroxene. The mesostasis glass has been completely leached out leaving voids. $\mathrm{Ch} 20(\mathrm{e}, \mathrm{f})$ is a Type I POP chondrule with plagioclase $\left(\mathrm{An}_{66}\right)$ interstitial to low-Ca pyroxene and some Ca-rich pyroxene. Smaller grains of Ca-rich pyroxene and glass are present in between the plagioclase laths as well as some areas of leached mesostasis glass that are replaced with void space.

Fig. 4. FIB section from Ch28 (see Fig. 3b). (a) HAADF image showing plagioclase (plg), Ca-rich pyroxene (cpx), and porous phyllosilicates (phy) interstitial to the plagioclase laths. Vertical banding is curtaining, a sample preparation artefact. (b) Close-up of the selected area in (a) illustrating zoning in the plagioclase laths and the relationship of zoning to grain boundaries, pores, and phyllosilicates. (c) $\mathrm{Ca} \mathrm{K \alpha}$ EDS image of the same region as (b) which illustrates the loss, and heterogeneous zoning, of $\mathrm{Ca}$ in the altered plagioclase.

Fig. 5. Compositions of plagioclase measured by EPMA. The range of measured plagioclase compositions in Semarkona chondrules is illustrated on the left. Each point represents the mean plagioclase composition in each chondrule. Error bars represent 1 standard deviation of the mean and the points are offset horizontally for ease of viewing. Individual analyses are plotted on a feldspar ternary on the right. The ternary is truncated at $\mathrm{Or}_{10}$ and the colors in the ternary correspond to those for the chondrule means on the left-hand side of the diagram.

Fig. 6. Results of equilibrium crystallization of chondrule bulk compositions in rhyolite-MELTS. Lines illustrate equilibrium plagioclase compositions with decreasing temperature (increasing crystallization). The average plagioclase composition measured in each chondrule is marked with a cross at the corresponding temperature. The plagioclase composition for $\mathrm{Ch} 36\left(\mathrm{An}_{99}\right)$ is not on the plagioclase crystallization line, so the crystallization temperature of anorthite in the Fo-Di-An system $\left(1317{ }^{\circ} \mathrm{C}\right)$ is plotted instead. Circles mark the temperatures at which Ca-rich pyroxene becomes stable. See text for details. 


\section{$\underline{\text { Supporting Information }}$}

Fig. S1. Data from EPMA maps of Ch3, Ch23, Ch20, and Ch36, used to determine bulk chondrule compositions. The anorthite content of primary plagioclase in these chondrules increases from left $\left(\mathrm{An}_{2}\right)$ to right $\left(\mathrm{An}_{99}\right)$. The first row shows BSE images for each chondrule. The second row shows phase maps highlighting the dominant phases of olivine (blue), low-Ca pyroxene (green), Ca-rich pyroxene (red), and mesostasis (white). Here, mesostasis consists of glass, plagioclase, and minor Ca-rich pyroxene. The third row shows atomic $\mathrm{Mg \#}$ maps illustrating the increase in $\mathrm{Mg \#}$ from left to right. Rows 4, 5, and 6 show quantitative wt. \% oxide maps of $\mathrm{Al}_{2} \mathrm{O}_{3}, \mathrm{CaO}$, and $\mathrm{Na}_{2} \mathrm{O}$, respectively.

Table S1. Individual EPMA analyses of feldspar in Semarkona chondrules. 
Table 1. Average feldspar compositions, ordered by increasing An content.

\begin{tabular}{|c|c|c|c|c|c|c|c|c|c|c|c|c|c|c|}
\hline & \multicolumn{2}{|c|}{ Chondrule 3} & \multicolumn{2}{|c|}{ Chondrule 28} & \multicolumn{2}{|c|}{ Chondrule 10} & \multicolumn{2}{|c|}{ Chondrule 33} & \multicolumn{2}{|c|}{ Chondrule 23} & \multicolumn{2}{|c|}{ Chondrule 47} & \multicolumn{2}{|c|}{ Chondrule 20} \\
\hline & wt. $\%$ & $1 \sigma$ & wt. $\%$ & $1 \sigma$ & wt. $\%$ & $1 \sigma$ & wt. $\%$ & $1 \sigma$ & wt. $\%$ & $1 \sigma$ & wt. $\%$ & $1 \sigma$ & wt. $\%$ & $1 \sigma$ \\
\hline $\mathrm{SiO}_{2}$ & 69.4 & 0.9 & 65.8 & 2.1 & 62.2 & 2.5 & 60.4 & 0.7 & 61.7 & 1.2 & 57.2 & 1.1 & 53.1 & 0.9 \\
\hline $\mathrm{Al}_{2} \mathrm{O}_{3}$ & 18.3 & 0.6 & 20.4 & 0.8 & 20.4 & 1.8 & 23.0 & 1.1 & 22.4 & 0.6 & 26.2 & 1.1 & 27.6 & 1.0 \\
\hline $\mathrm{Cr}_{2} \mathrm{O}_{3}$ & 0.01 & 0.01 & 0.02 & 0.01 & 0.04 & 0.02 & 0.02 & 0.01 & 0.08 & 0.05 & 0.04 & 0.04 & 0.05 & 0.03 \\
\hline $\mathrm{FeO}$ & 1.29 & 0.55 & 1.33 & 0.74 & 2.13 & 0.15 & 1.92 & 1.08 & 1.34 & 0.20 & 0.58 & 0.24 & 0.50 & 0.27 \\
\hline $\mathrm{MnO}$ & 0.04 & 0.02 & 0.04 & 0.02 & 0.03 & 0.01 & 0.06 & 0.04 & 0.18 & 0.07 & 0.07 & 0.06 & 0.14 & 0.04 \\
\hline $\mathrm{MgO}$ & 0.23 & 0.06 & 0.31 & 0.40 & 1.07 & 0.06 & 0.33 & 0.32 & 1.42 & 0.71 & 0.51 & 0.13 & 1.31 & 0.49 \\
\hline $\mathrm{CaO}$ & 0.41 & 0.17 & 2.15 & 1.15 & 5.71 & 1.59 & 6.61 & 0.35 & 7.03 & 0.82 & 9.50 & 0.82 & 13.2 & 0.7 \\
\hline $\mathrm{Na}_{2} \mathrm{O}$ & 11.3 & 0.6 & 10.3 & 0.7 & 8.50 & 1.20 & 7.50 & 0.29 & 6.48 & 0.40 & 6.09 & 0.36 & 3.73 & 0.24 \\
\hline $\mathrm{K}_{2} \mathrm{O}$ & 0.43 & 0.10 & 0.34 & 0.11 & 0.19 & 0.03 & 0.26 & 0.06 & 0.33 & 0.04 & 0.15 & 0.04 & 0.08 & 0.03 \\
\hline \multirow[t]{2}{*}{ Total } & 101.4 & 1.5 & 100.8 & 0.9 & 100.2 & 1.1 & 100.2 & 0.7 & 101.0 & 0.7 & 100.3 & 0.8 & 99.7 & 1.0 \\
\hline & \multicolumn{14}{|c|}{ formula based on 8 oxygens } \\
\hline $\mathrm{Si}$ & 3.01 & 0.01 & 2.89 & 0.06 & 2.79 & 0.09 & 2.71 & 0.02 & 2.73 & 0.05 & 2.57 & 0.05 & 2.42 & 0.04 \\
\hline $\mathrm{Al}$ & 0.94 & 0.02 & 1.06 & 0.05 & 1.08 & 0.10 & 1.22 & 0.05 & 1.17 & 0.03 & 1.38 & 0.05 & 1.48 & 0.05 \\
\hline $\mathrm{Cr}$ & 0.00 & 0.00 & 0.00 & 0.00 & 0.00 & 0.00 & 0.00 & 0.00 & 0.00 & 0.00 & 0.00 & 0.00 & 0.00 & 0.00 \\
\hline $\mathrm{Fe}$ & 0.05 & 0.02 & 0.05 & 0.03 & 0.08 & 0.01 & 0.07 & 0.04 & 0.05 & 0.01 & 0.02 & 0.01 & 0.02 & 0.01 \\
\hline $\mathrm{Mn}$ & 0.00 & 0.00 & 0.00 & 0.00 & 0.00 & 0.00 & 0.00 & 0.00 & 0.01 & 0.00 & 0.00 & 0.00 & 0.01 & 0.00 \\
\hline $\mathrm{Mg}$ & 0.01 & 0.00 & 0.02 & 0.03 & 0.07 & 0.01 & 0.02 & 0.02 & 0.09 & 0.05 & 0.03 & 0.01 & 0.09 & 0.03 \\
\hline $\mathrm{Ca}$ & 0.02 & 0.01 & 0.10 & 0.05 & 0.27 & 0.08 & 0.32 & 0.02 & 0.33 & 0.04 & 0.46 & 0.04 & 0.64 & 0.03 \\
\hline $\mathrm{Na}$ & 0.95 & 0.03 & 0.88 & 0.05 & 0.74 & 0.11 & 0.65 & 0.02 & 0.56 & 0.04 & 0.53 & 0.03 & 0.33 & 0.02 \\
\hline K & 0.02 & 0.01 & 0.02 & 0.01 & 0.01 & 0.00 & 0.01 & 0.00 & 0.02 & 0.00 & 0.01 & 0.00 & 0.00 & 0.00 \\
\hline Total & 5.01 & 0.02 & 5.03 & 0.02 & 5.05 & 0.03 & 5.01 & 0.02 & 4.97 & 0.04 & 5.01 & 0.01 & 5.00 & 0.01 \\
\hline An & 1.9 & 0.8 & 10.1 & 5.4 & 26.9 & 8.3 & 32.3 & 1.6 & 36.7 & 3.2 & 45.9 & 3.5 & 65.8 & 2.1 \\
\hline $\mathrm{Ab}$ & 95.7 & 0.7 & 88.0 & 5.1 & 72.0 & 8.2 & 66.2 & 1.6 & 61.2 & 3.1 & 53.3 & 3.3 & 33.7 & 2.0 \\
\hline Or & 2.4 & 0.6 & 1.9 & 0.6 & 1.0 & 0.1 & 1.5 & 0.4 & 2.1 & 0.4 & 0.9 & 0.3 & 0.5 & 0.2 \\
\hline $\mathrm{n}^{1}$ & 4 & & 11 & & 3 & & 8 & & 3 & & 8 & & 5 & \\
\hline
\end{tabular}

${ }^{1} \mathrm{n}=$ number of analyses 
Table 1. (Continued). Average feldspar compositions, ordered by increasing An content.

\begin{tabular}{|c|c|c|c|c|c|c|c|c|c|c|c|c|c|c|}
\hline & \multicolumn{2}{|c|}{ Chondrule 41} & \multicolumn{2}{|c|}{ Chondrule 26} & \multicolumn{2}{|c|}{ Chondrule 30} & \multicolumn{2}{|c|}{ Chondrule 1} & \multicolumn{2}{|c|}{ Chondrule 68} & \multicolumn{2}{|c|}{ Chondrule 36} & \multicolumn{2}{|c|}{ Chondrule 22} \\
\hline & wt. $\%$ & $1 \sigma$ & wt. $\%$ & $1 \sigma$ & wt. $\%$ & $1 \sigma$ & wt. $\%$ & $1 \sigma$ & wt. $\%$ & $1 \sigma$ & wt. $\%$ & $1 \sigma$ & wt. $\%$ & $1 \sigma$ \\
\hline $\mathrm{SiO}_{2}$ & 52.6 & 1.3 & 46.2 & 1.1 & 48.8 & 0.8 & 49.9 & 0.6 & 44.3 & 1.1 & 48.3 & 0.7 & 44.8 & 0.6 \\
\hline $\mathrm{Al}_{2} \mathrm{O}_{3}$ & 28.5 & 1.0 & 32.6 & 2.2 & 30.4 & 1.5 & 30.9 & 0.8 & 34.0 & 1.9 & 30.0 & 1.3 & 35.5 & 0.6 \\
\hline $\mathrm{Cr}_{2} \mathrm{O}_{3}$ & 0.04 & 0.02 & 0.03 & 0.02 & 0.06 & 0.03 & 0.03 & 0.03 & 0.05 & 0.06 & 0.02 & 0.02 & 0.02 & 0.02 \\
\hline $\mathrm{FeO}$ & 1.03 & 0.59 & 0.90 & 0.92 & 0.49 & 0.25 & 0.43 & 0.20 & 0.17 & 0.14 & 0.20 & 0.15 & 1.03 & 0.19 \\
\hline $\mathrm{MnO}$ & 0.10 & 0.06 & 0.06 & 0.04 & 0.05 & 0.05 & 0.02 & 0.02 & 0.03 & 0.03 & 0.01 & 0.01 & 0.03 & 0.02 \\
\hline $\mathrm{MgO}$ & 0.99 & 0.37 & 1.64 & 1.17 & 1.83 & 1.08 & 1.82 & 0.68 & 1.20 & 1.26 & 2.19 & 0.37 & 0.73 & 0.20 \\
\hline $\mathrm{CaO}$ & 13.3 & 1.0 & 17.8 & 1.3 & 17.6 & 0.5 & 18.3 & 0.3 & 19.5 & 0.4 & 19.4 & 0.3 & 19.8 & 0.2 \\
\hline $\mathrm{Na}_{2} \mathrm{O}$ & 3.61 & 0.36 & 0.84 & 0.42 & 0.60 & 0.17 & 0.22 & 0.09 & 0.22 & 0.07 & 0.10 & 0.07 & 0.04 & 0.03 \\
\hline $\mathrm{K}_{2} \mathrm{O}$ & 0.09 & 0.03 & 0.07 & 0.04 & 0.07 & 0.06 & 0.03 & 0.01 & 0.04 & 0.02 & 0.03 & 0.02 & 0.04 & 0.01 \\
\hline \multirow[t]{2}{*}{ Total } & 100.2 & 0.9 & 100.2 & 1.3 & 99.9 & 0.8 & 101.7 & 0.7 & 99.4 & 0.6 & 100.3 & 0.7 & 102.1 & 0.3 \\
\hline & \multicolumn{14}{|c|}{ formula based on 8 oxygens } \\
\hline $\mathrm{Si}$ & 2.39 & 0.05 & 2.13 & 0.05 & 2.24 & 0.04 & 2.25 & 0.02 & 2.06 & 0.05 & 2.22 & 0.04 & 2.04 & 0.03 \\
\hline $\mathrm{Al}$ & 1.53 & 0.05 & 1.77 & 0.10 & 1.65 & 0.07 & 1.64 & 0.04 & 1.87 & 0.11 & 1.62 & 0.06 & 1.91 & 0.03 \\
\hline $\mathrm{Cr}$ & 0.00 & 0.00 & 0.00 & 0.00 & 0.00 & 0.00 & 0.00 & 0.00 & 0.00 & 0.00 & 0.00 & 0.00 & 0.00 & 0.00 \\
\hline $\mathrm{Fe}$ & 0.04 & 0.02 & 0.03 & 0.04 & 0.02 & 0.01 & 0.02 & 0.01 & 0.01 & 0.01 & 0.01 & 0.01 & 0.04 & 0.01 \\
\hline $\mathrm{Mn}$ & 0.00 & 0.00 & 0.00 & 0.00 & 0.00 & 0.00 & 0.00 & 0.00 & 0.00 & 0.00 & 0.00 & 0.00 & 0.00 & 0.00 \\
\hline $\mathrm{Mg}$ & 0.07 & 0.03 & 0.11 & 0.08 & 0.13 & 0.07 & 0.12 & 0.05 & 0.08 & 0.09 & 0.15 & 0.03 & 0.05 & 0.01 \\
\hline $\mathrm{Ca}$ & 0.65 & 0.05 & 0.88 & 0.05 & 0.86 & 0.02 & 0.89 & 0.01 & 0.97 & 0.02 & 0.96 & 0.01 & 0.97 & 0.01 \\
\hline $\mathrm{Na}$ & 0.32 & 0.03 & 0.08 & 0.04 & 0.05 & 0.02 & 0.02 & 0.01 & 0.02 & 0.01 & 0.01 & 0.01 & 0.00 & 0.00 \\
\hline K & 0.01 & 0.00 & 0.00 & 0.00 & 0.00 & 0.00 & 0.00 & 0.00 & 0.00 & 0.00 & 0.00 & 0.00 & 0.00 & 0.00 \\
\hline Total & 5.00 & 0.02 & 5.02 & 0.02 & 4.96 & 0.03 & 4.94 & 0.02 & 5.02 & 0.02 & 4.97 & 0.01 & 5.01 & 0.01 \\
\hline An & 66.6 & 4.0 & 91.7 & 4.3 & 93.8 & 1.7 & 97.7 & 0.8 & 97.8 & 0.8 & 98.9 & 0.7 & 99.5 & 0.2 \\
\hline $\mathrm{Ab}$ & 32.8 & 3.8 & 7.9 & 4.1 & 5.7 & 1.5 & 2.1 & 0.8 & 2.0 & 0.7 & 1.0 & 0.6 & 0.3 & 0.3 \\
\hline Or & 0.6 & 0.2 & 0.4 & 0.3 & 0.4 & 0.4 & 0.2 & 0.1 & 0.2 & 0.1 & 0.2 & 0.1 & 0.2 & 0.0 \\
\hline $\mathrm{n}^{1}$ & 3 & & 5 & & 6 & & 16 & & 7 & & 15 & & 4 & \\
\hline
\end{tabular}

${ }^{1} \mathrm{n}=$ number of analyses 
Table 2. Bulk silicate compositions of selected chondrules.

\begin{tabular}{|c|c|c|c|c|}
\hline & $\begin{array}{r}\text { Ch3 } \\
\text { Type II }\end{array}$ & $\begin{array}{r}\text { Ch23 } \\
\text { Type I }\end{array}$ & $\begin{array}{r}\text { Ch20 } \\
\text { Type I }\end{array}$ & $\begin{array}{r}\text { Ch36 } \\
\text { BO }\end{array}$ \\
\hline $\mathrm{SiO}_{2}$ & 45.4 & 52.1 & 53.9 & 43.4 \\
\hline $\mathrm{Al}_{2} \mathrm{O}_{3}$ & 2.08 & 2.44 & 2.50 & 6.93 \\
\hline $\mathrm{Cr}_{2} \mathrm{O}_{3}$ & 0.63 & 0.78 & 0.71 & 0.25 \\
\hline $\mathrm{FeO}$ & 16.3 & 5.31 & 3.43 & 1.76 \\
\hline $\mathrm{MgO}$ & 32.7 & 36.7 & 37.1 & 41.7 \\
\hline $\mathrm{CaO}$ & 1.58 & 1.99 & 1.91 & 5.65 \\
\hline $\mathrm{Na}_{2} \mathrm{O}$ & 1.21 & 0.59 & 0.40 & 0.28 \\
\hline $\mathrm{K}_{2} \mathrm{O}$ & 0.13 & 0.08 & 0.07 & 0.07 \\
\hline Total & 100.0 & 100.0 & 100.0 & 100.0 \\
\hline $\mathrm{Mg \#}^{1}$ & 66.8 & 87.4 & 91.5 & 95.9 \\
\hline $\mathrm{Mg}^{2}$ & 78.2 & 92.5 & 95.1 & 97.7 \\
\hline $\mathrm{Na} / \mathrm{Al}^{3}$ & 1.1 & 0.5 & 0.3 & 0.1 \\
\hline $\mathrm{Ca} / \mathrm{Al}^{3}$ & 1.4 & 1.5 & 1.4 & 1.5 \\
\hline $\mathrm{An}^{4}$ & 1.9 & 36.7 & 65.8 & 98.9 \\
\hline Liquidus $^{5}$ & $1672^{\circ} \mathrm{C}$ & $1688^{\circ} \mathrm{C}$ & $1685^{\circ} \mathrm{C}$ & $1744^{\circ} \mathrm{C}$ \\
\hline & \multicolumn{4}{|c|}{ Modal mineral abundances 6} \\
\hline Olivine & $63 \%$ & $27 \%$ & $19 \%$ & $66 \%$ \\
\hline Low-Ca pyx & $13 \%$ & $57 \%$ & $66 \%$ & $0 \%$ \\
\hline Ca-rich pyx & $14 \%$ & $7 \%$ & $7 \%$ & $2 \%$ \\
\hline Mesostasis ${ }^{7}$ & $10 \%$ & $9 \%$ & $8 \%$ & $32 \%$ \\
\hline $\begin{array}{l}{ }^{1} \mathrm{Mg} \#=\mathrm{Mg} /(\mathrm{N} \\
{ }^{2} \mathrm{Mg} \#=\mathrm{Mg} /(\mathrm{N} \\
{ }^{3} \text { atomic } \\
{ }^{4} \text { average plagi } \\
{ }^{5} \text { estimated usin } \\
{ }^{6} \text { estimated fror } \\
{ }^{7} \text { includes glass }\end{array}$ & $\begin{array}{l}\mathrm{g}+\mathrm{Fe}) \times 10 \\
\mathrm{~g}+\mathrm{Fe}) \times 10 \\
\text { clase com } \\
\text { Rhyolite } \\
\text { EPMA m } \\
\text { plagiocla }\end{array}$ & $\begin{array}{l}\text { wt. \% oxic } \\
\text { atomic } \\
\text { sitions, frc } \\
\text { IELTS } \\
\text { s (see Fig }\end{array}$ & $\begin{array}{l}\text { n Table } 1 \\
\text { S1) }\end{array}$ & \\
\hline
\end{tabular}




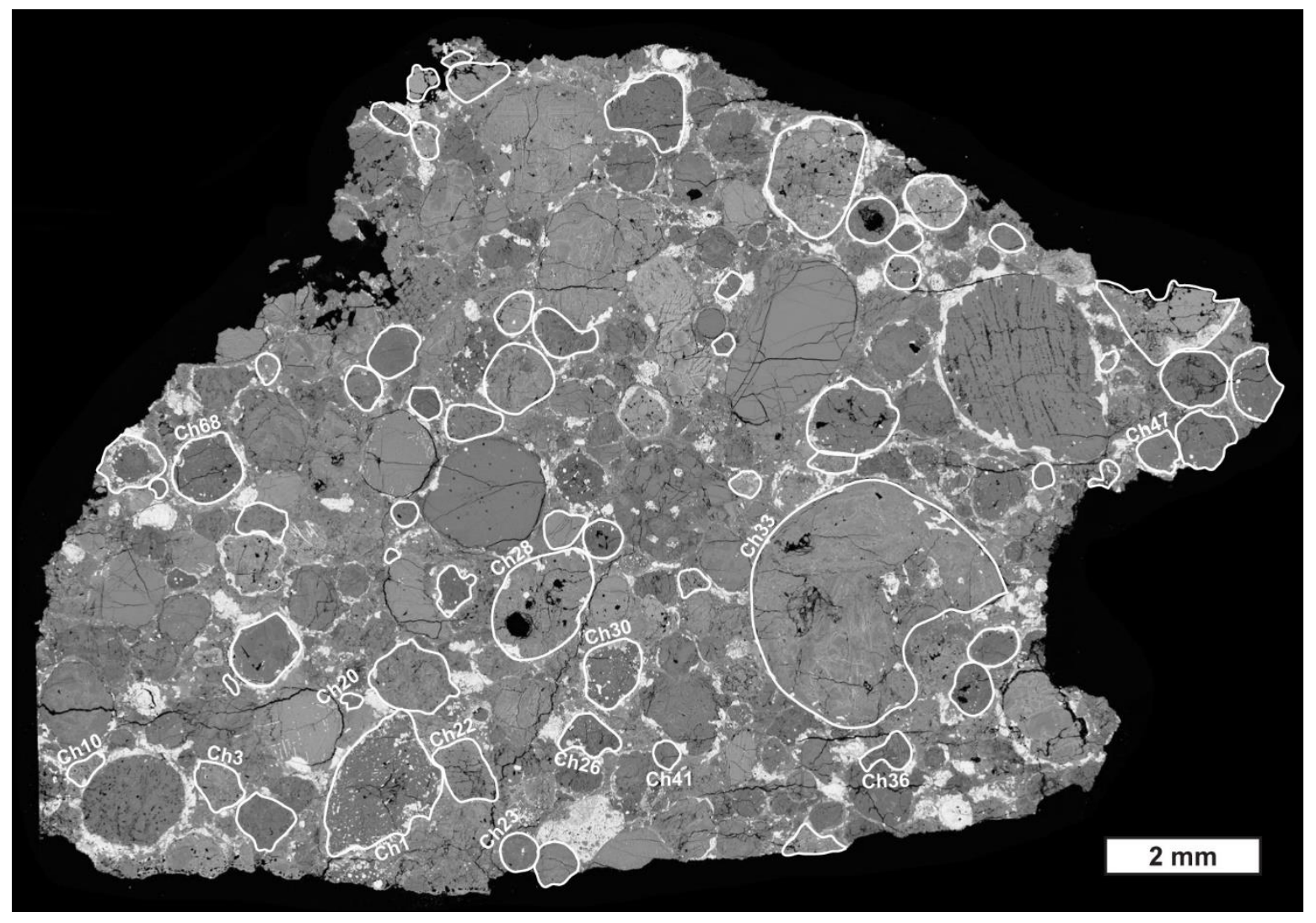


Chondrule 3
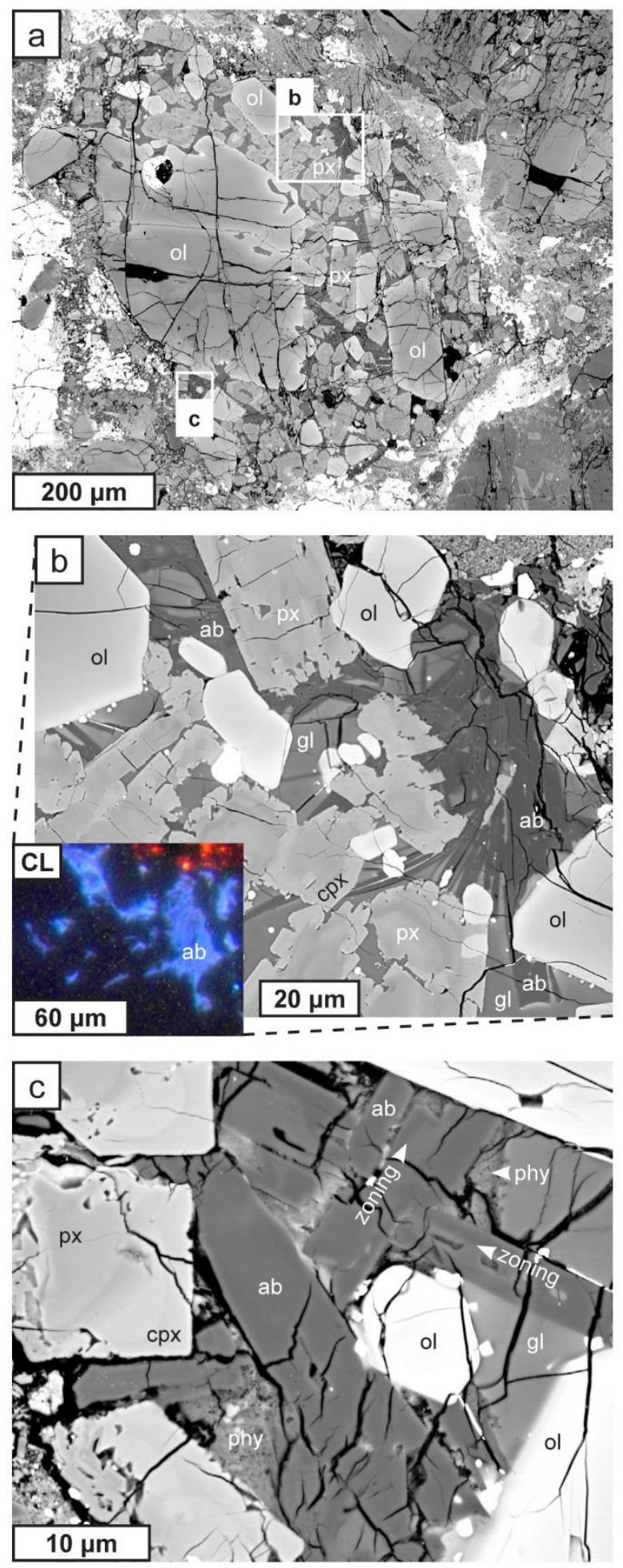

Chondrule 36
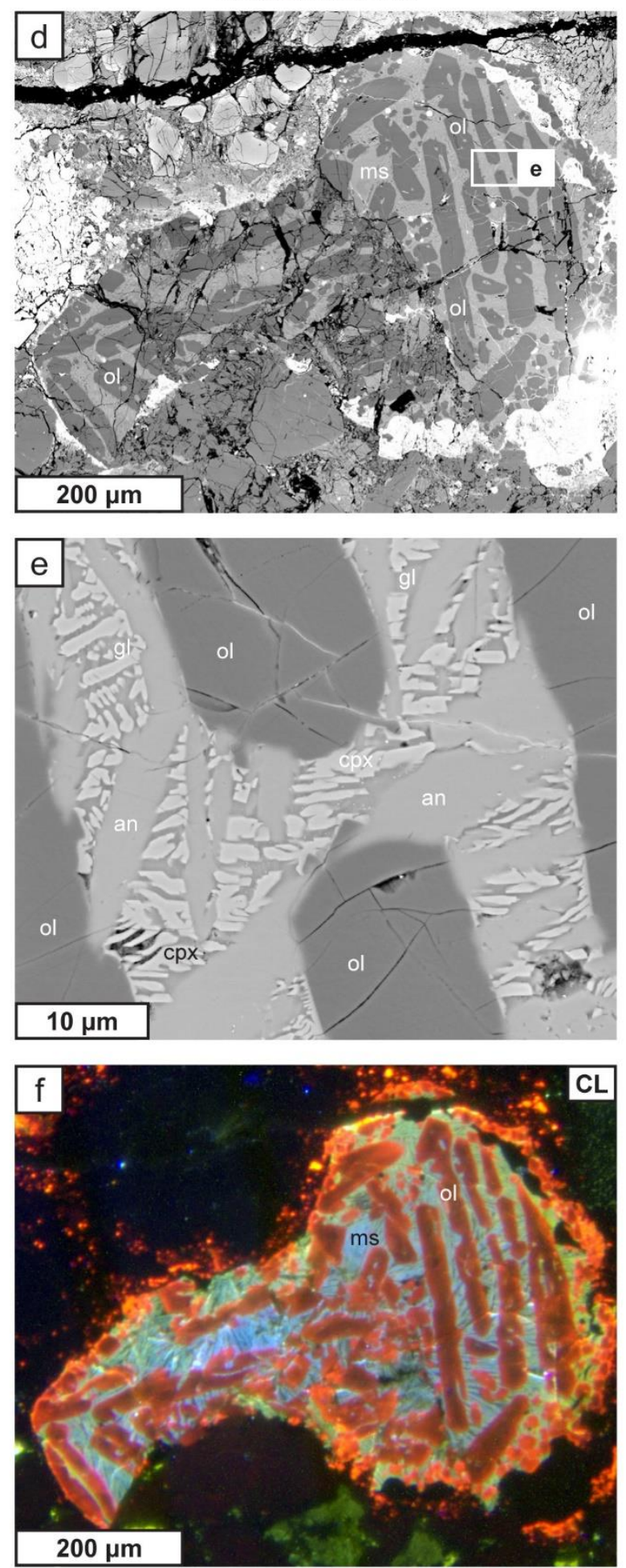

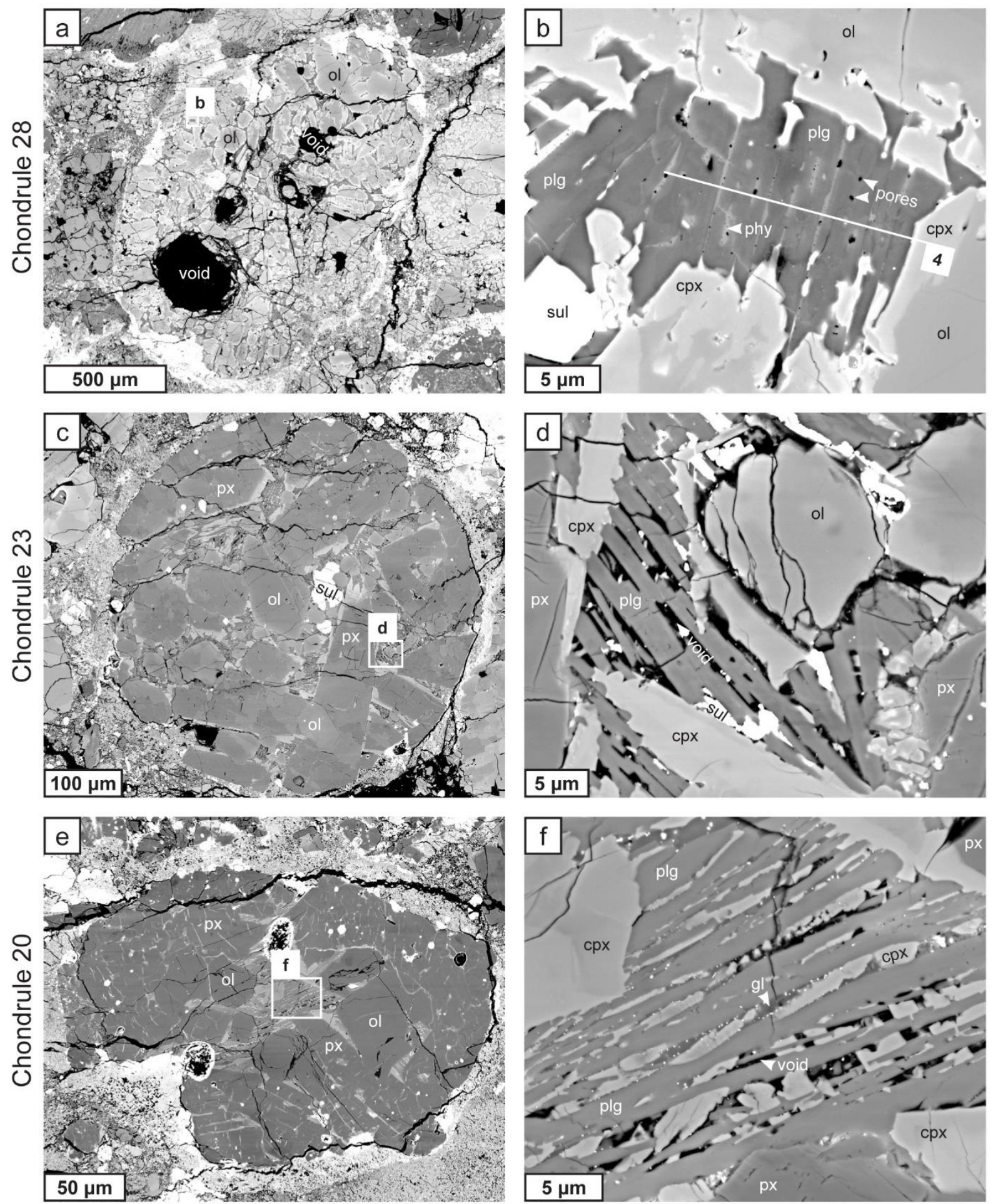

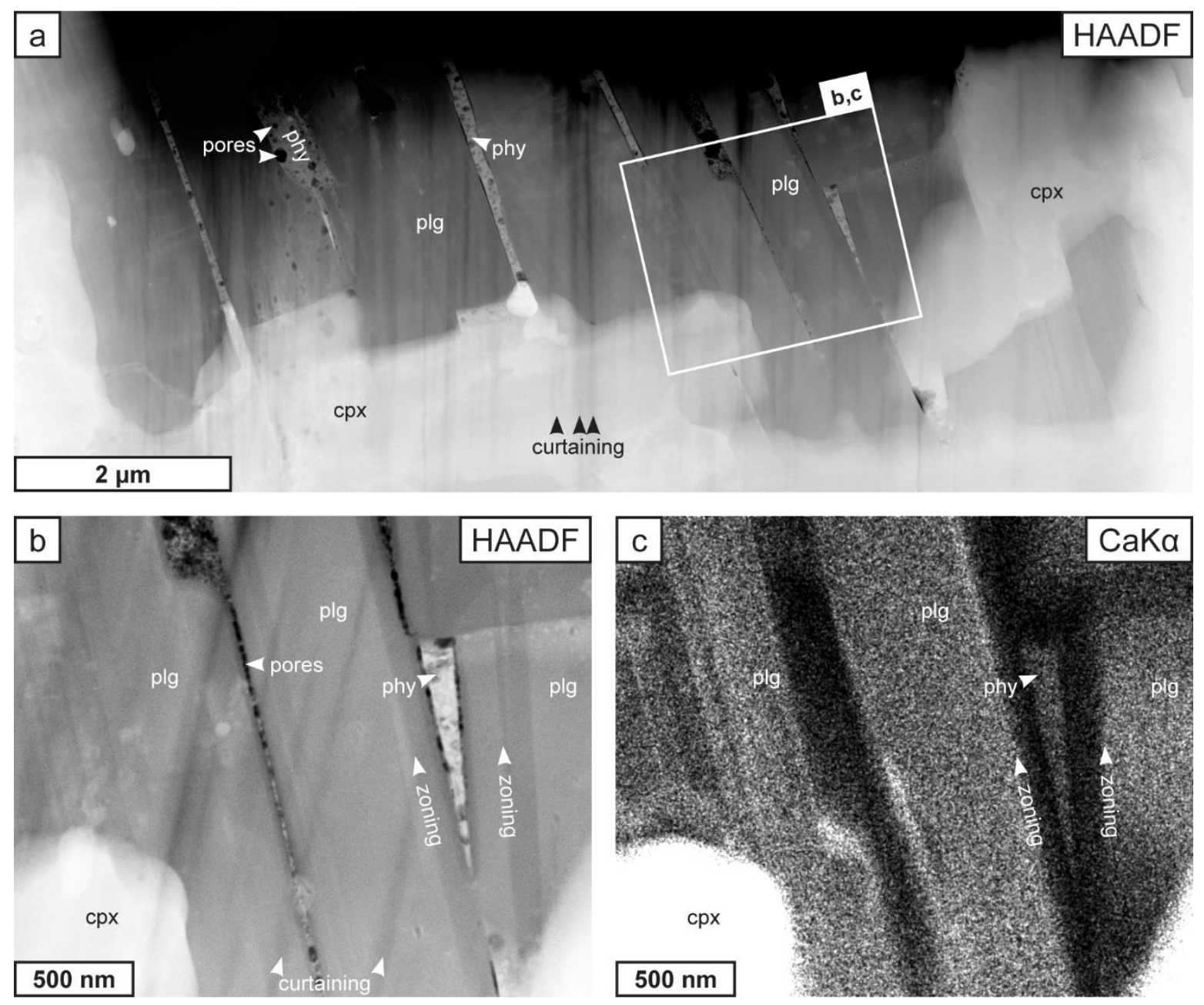


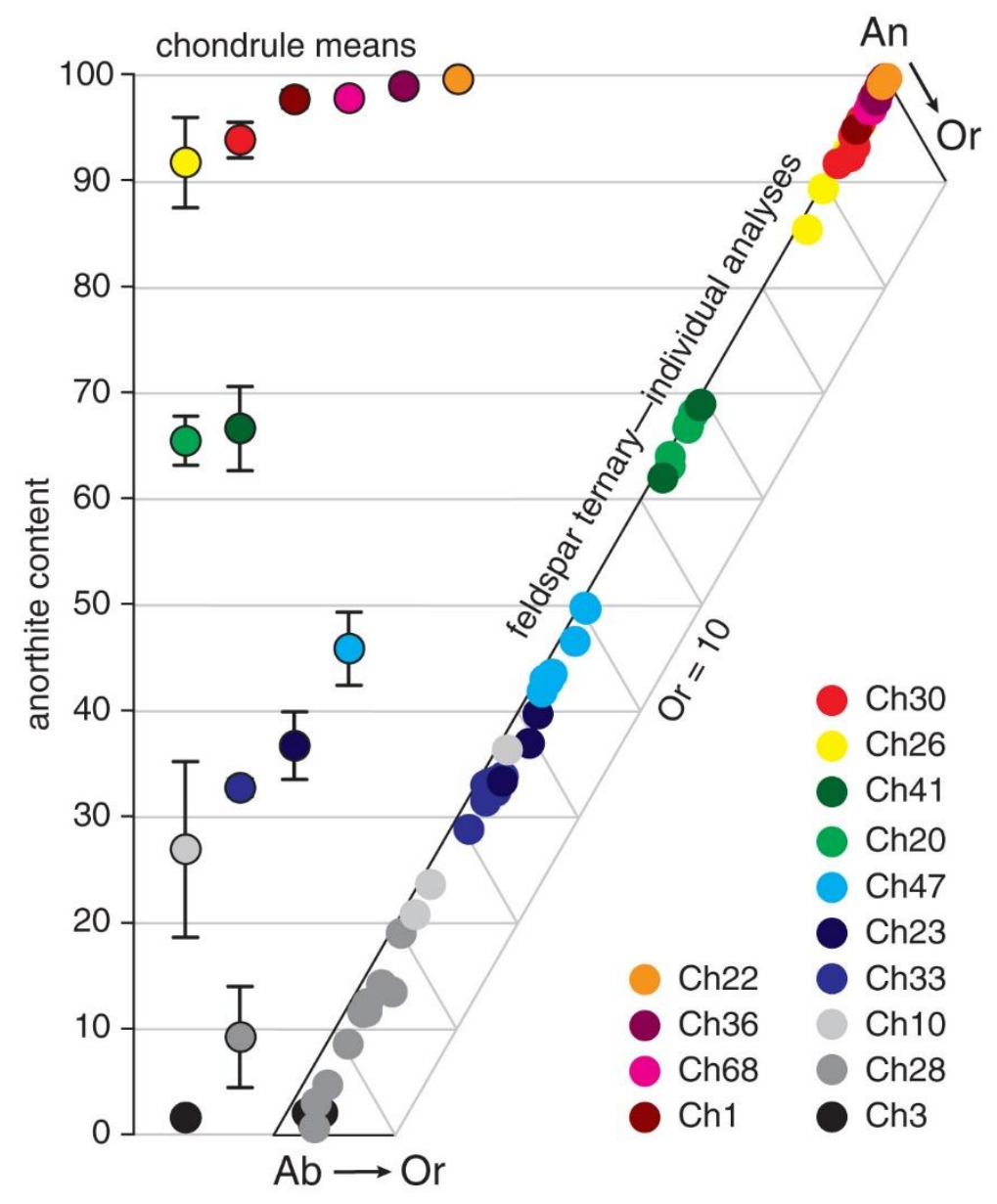




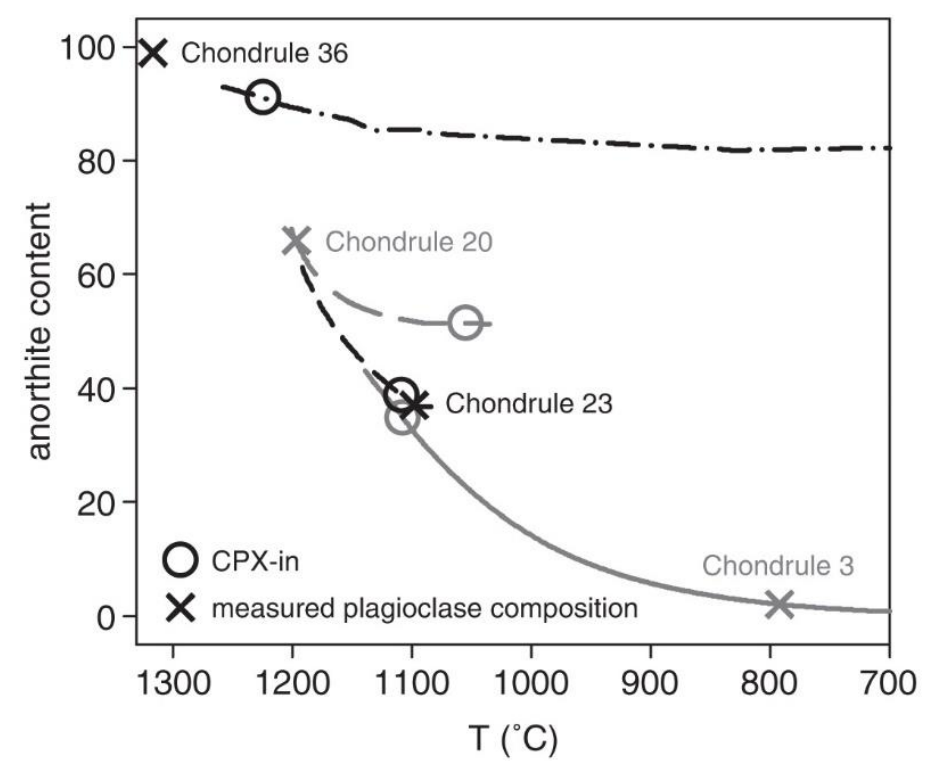



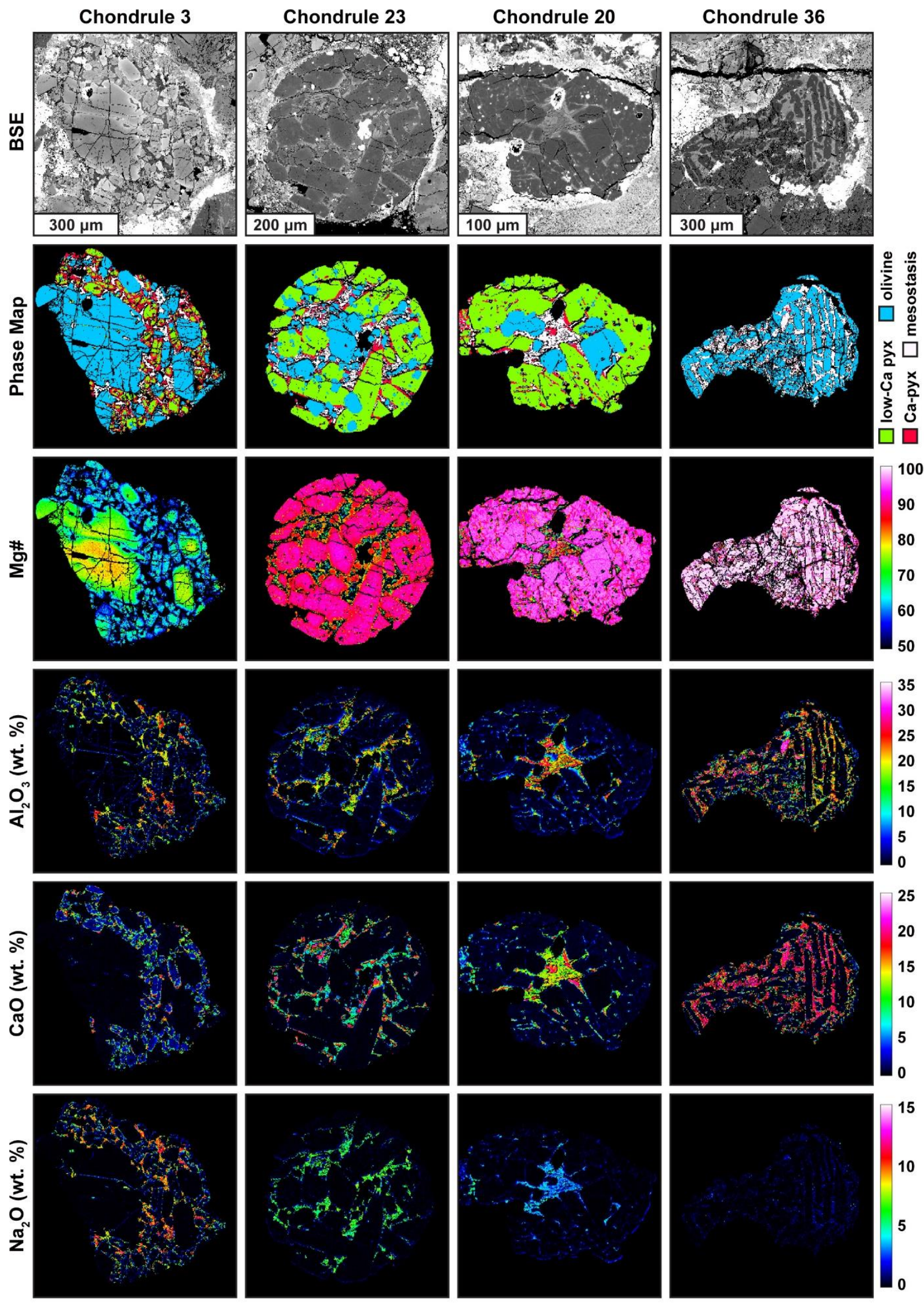